\title{
Financing and takeovers
}

\author{
Erwan Morellec ${ }^{\mathrm{a}, \mathrm{b}, *}$, Alexei Zhdanov ${ }^{\mathrm{a}, \mathrm{c}}$ \\ ${ }^{a}$ University of Lausanne and Swiss Finance Institute, Switzerland \\ ${ }^{\mathrm{b}} \mathrm{CEPR}, U K$ \\ ${ }^{\mathrm{c}}$ School of Management, George Mason University, Fairfax VA, 22030, USA
}

Received 17 May 2006; received in revised form 26 October 2006; accepted 23 January 2007

Available online 14 December 2007

\begin{abstract}
This paper analyzes the interaction between financial leverage and takeover activity. We develop a dynamic model of takeovers in which the financing strategies of bidding firms and the timing and terms of takeovers are jointly determined. In the paper, capital structure plays the role of a commitment device, and determines the outcome of the acquisition contest. We demonstrate that there exists an asymmetric equilibrium in financing policies with endogenous leverage, bankruptcy, and takeover terms, in which the bidder with the lowest leverage wins the takeover contest. Based on the resulting equilibrium, the model generates a number of new predictions. In particular, the model predicts that the leverage of the winning bidder is below the industry average and that acquirers should lever up after the takeover consummation. The model also relates the dispersion in leverage ratios to various industry characteristics, such as cash flow volatility or bankruptcy costs.
\end{abstract}

(C) 2008 Published by Elsevier B.V.

JEL classification: G13; G32; G34

Keywords: Takeovers; Option games; Real options; Capital structure

\section{Introduction}

The literature on mergers and acquisitions is extensive. Yet a number of dimensions of the merger process still lack proper understanding. For example, while existing models provide a rich intuition as to why firms should merge or restructure, they have not been entirely successful at explaining the relation between financial leverage and takeovers. Various theories relate a firm's incentive to merge to capital structure motives based

\footnotetext{
${ }^{2}$ We are grateful to Mike Barclay, Assaf Eisdorfer, Evan Dudley, Evgeny Lyandres, Lukasz Pomorski, Michael Roberts, Clifford W. Smith, Neng Wang, and especially the anonymous referee and Laurent Frésard for helpful comments. Comments from seminar participants at the University of Rochester, the University of British Columbia, the University of Toronto, the University of Buffalo, and George Mason University are also gratefully acknowledged. The first author acknowledges financial support from the Swiss Finance Institute and from NCCR FINRISK of the Swiss National Science Foundation.

*Corresponding author at: Ecole des HES, University of Lausanne, Rte de Chavannes 33, 1007 Lausanne, Switzerland. Tel.: + 410216923357 ; fax: + 410216923435 .

E-mail addresses: erwan.morellec@unil.ch (E. Morellec), azhdanov@gmu.edu (A. Zhdanov).
} 
on tax shields, wealth transfers, financial slack, or information asymmetry. However, no theory examines the link between capital structure and the timing and terms of takeovers or the outcome of bidding contests in takeover deals. In this paper we propose such a theory, while incorporating traditional determinants of firms' financing policies such as tax shields and costly foreclosure.

A prerequisite for our analysis is a model that captures in a simple fashion the impact of financing on valuations. In this paper, we base our analysis on a contingent claims model in the spirit of Mello and Parsons (1992), in which financing policy affects firm value through its impact on taxes, bankruptcy costs, and investment policy. While Mello and Parsons focus on internal investment, we consider instead growth via acquisition in an environment in which several firms can compete for a target. In the paper, the financing strategies of the bidding firms and the timing and terms of takeovers are jointly determined. We show that capital structure plays the role of a commitment device and determines the outcome of the acquisition contest. Notably, we demonstrate that there exists an asymmetric equilibrium in financing policies with endogenous leverage, bankruptcy, and takeover terms. In this equilibrium, the bidder with the lowest leverage wins the takeover contest. The other bidders make up for the loss of the growth opportunity by issuing more debt and receiving greater tax benefits.

Based on the resulting equilibrium the model yields a number of new predictions. Specifically, the model demonstrates that potential control transactions (and more generally potential investment opportunities) could lead otherwise identical firms to select different financing strategies. In addition, the model relates the dispersion in leverage ratios to various industry characteristics such as bankruptcy costs or cash flow volatility. The model also predicts that the leverage of the winning bidder is below the industry average and that acquirers should lever up after the takeover consummation. The predictions of the model for firm-level financing strategies are consistent with the available evidence on the relation between financing and takeovers. ${ }^{1}$ The predictions on the dispersion in industry leverage ratios are novel and provide grounds for further empirical work on mergers and acquisitions.

While our model is specifically tailored to takeover transactions, it can be applied to any investment opportunity available to a set of competing firms. In our asymmetric equilibrium one firm decides to have a lower leverage ratio to receive some of the net present value of the investment opportunity. The other firm makes up for the lost opportunity by selecting a higher debt level, which is associated with greater tax benefits. Thus, in the model two ex ante identical firms optimally choose asymmetric strategies. One becomes a growth firm, selects a low leverage ratio, and invests. The other becomes a value firm, selects a higher leverage ratio, and does not invest. In this equilibrium the growth firm ends up with a lower leverage ratio, which is consistent with the available empirical evidence on firm's financing policies (see Smith and Watts, 1992; Rajan and Zingales, 1995). ${ }^{2}$

The analysis in the present paper relates to several articles in the literature. Lambrecht (2004), Morellec and Zhdanov (2005), Lambrecht and Myers (2007), Margsiri, Mello, and Ruckes (2005), and Hackbarth and Morellec (2008) develop real options models to analyze the timing and terms of takeovers. In all of these papers, firms are unlevered. Morellec (2004) and Leland (2007) examine the relation between the debt structure of target firms and control transactions. Morellec (2004) considers a model in which managers of target firms do not act in the best interests of shareholders. In his model debt serves as a defensive device to prevent control challenges and control transactions do not arise in equilibrium. Leland (2007) abstracts from agency conflicts and considers the role of purely financial synergies in motivating mergers and acquisitions in a model with exogenous timing.

While our model shares some characteristics with these in existing literature, it also differs from them in a number of important dimensions. First, the present model examines the outcome of takeover contests when both the bidding and the target firms are levered. As we show in the paper, the financing strategies of

\footnotetext{
${ }^{1}$ Bruner (1988), Ghosh and Jain (2000), and Uysal (2006) show that bidders are significantly less levered before mergers than a control sample of firms and that the bidders' leverage rises significantly after the takeover consummation. Welch (2004) reports that "firms that have engaged in takeover activity tend to increase leverage." Clayton and Ravid (2002) find empirical support for the prediction that firms with higher leverage are likely to lose bidding contests.

${ }^{2}$ Our results are also consistent with the evidence on leverage, product market competition, and investment. For example, Chevalier (1995) reports that unleveraged supermarket chains are more likely to open stores where competitors have recently experienced a leveraged buyout. Kovenock and Phillips (1997) find that highly leveraged firms in concentrated industries are less likely to increase investment.
} 
participating firms have a large impact on the timing and terms of mergers and acquisitions. In addition, with the exception of Leland (2007) and Morellec (2004) in which the timing and terms of takeovers are exogenous, the cited works do not focus on taxes, default costs, and optimal capital structure, which are central to our analysis. Finally, unlike prior work we account for competition among bidding firms. Competition plays an important role in shaping equilibrium financing strategies. If there is no competition among bidders, then the strategic role of debt disappears.

Our paper also relates to the literature that examines the relation between growth options and debt financing (see Myers, 1977; Barclay, Morellec, and Smith, 2006). In this literature, the cost of investment is exogenous and firms have a monopoly access to investment projects. By contrast, our model derives the cost of investment endogenously, as the solution to the maximization problem of target shareholders. In addition, our model incorporates the impact of competition on the timing and terms of investment decisions and emphasizes the role of capital structure as a commitment device in takeover contests. As shown in the paper, these differences have important implications for equilibrium financing strategies. Finally, our paper also contributes to the literature that examines the relation between competition and capital structure within contingent claims models by considering the impact of investment opportunities on financing strategies (see Lambrecht, 2001; Miao, 2005; Zhdanov, 2007).

The remainder of the paper is organized as follows. The basic model of takeovers is developed in Section 2, where we also derive equilibrium financing strategies. Section 3 extends the model to incorporate imperfect information. Section 4 reviews the paper's empirical implications in light of the empirical evidence on the relation between financing decisions and control transactions and provides concluding remarks.

\section{The model}

Consider an industry with three different firms: two potential acquirers and a potential target. These roles are exogenously assigned and are determined by firms' specific characteristics, not modeled in this paper. Each firm is risk-neutral and has rational expectations about the underlying stochastic processes and the decision rules of other firms. Because of the tax benefits of debt, these firms are financed with both debt and equity. Their choice of financing strategy is determined by balancing the tax advantage of debt with expected bankruptcy costs. It also reflects the strategic role of debt, i.e., its impact on the outcome of the takeover contest.

The potential acquirers have identical operating technologies and their profits are subject to the same industry shock $X$. However, they can freely choose their financing strategies. As shown below, potential takeover contests lead these firms to select different leverage ratios. In the base version of the model we focus on equity financed cash offers. That is, we assume that the winner of the takeover contest issues new equity and the proceeds of this issue are used to pay a cash settlement to target shareholders. In the Appendix, we extend the model to examine stock offers.

Firms in the industry are infinitely lived (ignoring default) and have assets that generate a continuous stream of cash flows. Before the takeover, the instantaneous profit of bidder $i$ is given by $(1-\tau)\left(\Pi_{i, b} X-c_{i, b}\right)$, for $i=1,2$, where $\Pi_{i, b}>0$ is a constant scaling factor, $c_{i, b}$ is the contractual coupon payment of bidder $i$, and $\tau$ is the corporate tax rate. To make sure that our results are not driven by size effects we consider that $\Pi_{1, b}=\Pi_{2, b}=\Pi_{b}$. In addition, we assume that the industry shock $\left(X_{t}\right)_{t \geqslant 0}$ is governed by the stochastic process

$$
\mathrm{d} X_{s}=\mu X_{s} \mathrm{~d} s+\sigma X_{s} \mathrm{~d} W_{s}, \quad X_{0}=x,
$$

where $\mu$ and $\sigma>0$ are constant parameters and $\left(W_{s}\right)_{s \geqslant 0}$ is a standard Brownian motion. This equation implies that the growth rate of cash flows is normally distributed with mean $\mu \Delta t$ and variance $\sigma^{2} \Delta t$ over the time interval $\Delta t$. The target's instantaneous profit is subject to the same industry shock $X$ and is given by $(1-\tau)\left(\Pi_{\mathrm{tar}} X-c_{\mathrm{tar}}\right)$, where $\Pi_{\mathrm{tar}}>0$ and $c_{\mathrm{tar}}$ is the coupon payment of the target firm.

After the takeover, the new entity has to assume the debt obligations of the target. As a result, the instantaneous profit of the combined entity is given by

$$
(1-\tau)\left[\Pi_{m} X-c_{i, m}\right],
$$


where $\Pi_{m}>0$ and $c_{i, m}=c_{i, b}+c_{\text {tar }}$ is the coupon payment of the merged entity. Typically, acquisitions generate gains that might be related to a better utilization of production facilities, a greater market power, or economies of scale(see, e.g., Mitchell and Mulherin, 1996; Andrade, Mitchell, and Stafford, 2001; or Andrade and Stafford, 2004). It is therefore natural to assume that $\Pi_{m}=\Pi_{b}+\Pi_{\operatorname{tar}}+\Lambda$, where $\Lambda>0$ represents the benefits from the acquisition. Because part of this improvement in value could come at the expense of other firms in the industry, we assume that the losing bidder suffers a reduction in operating cash flow from $\Pi_{b} X$ to $\Pi_{o} X$, with $\Pi_{o} \in\left[\Pi_{b}-\Lambda, \Pi_{b}\right]$, after the takeover. ${ }^{3}$

Throughout the analysis, there exists an instantaneous risk-free rate $r>\mu$ at which investors could lend and borrow freely. In addition, we assume that $c_{\operatorname{tar}} /\left(\Pi_{m}-\Pi_{o}\right)<c_{i, b} / \Pi_{o}$. This condition is satisfied, for example, if the target firm chooses an optimal leverage (our base case). We also examine the case in which $c_{\mathrm{tar}} /\left(\Pi_{m}-\Pi_{o}\right)>c_{i, b} / \Pi_{o}$ and show that it corresponds to situations in which the target is extremely leveraged. Finally, we abstract from potential agency conflicts between managers and shareholders by assuming that the incentives of these two groups are perfectly aligned (see Zwiebel, 1996; Morellec, 2004, for an analysis of the relation between agency conflicts, financing decisions, and control transactions).

\subsection{Leverage and the outcome of the takeover contest}

In our model shareholders make three types of interrelated decisions. First, they select the firm's financing strategy. Second, they select the timing and terms of takeovers. Third, they select the firm's default policy. Assume that the takeover is consummated today. (Below we determine the timing of the takeover endogenously.) The question we want to address is whether the capital structures of the bidding firms can help identify the winning bidder. We solve the model using backward induction, starting with the values of participating firms after the takeover.

At this stage we assume that firms do not change their debt levels upon the takeover consummation. This implies that, after the takeover, shareholders' only decision is to select the firm's default policy. Throughout the paper, we consider a stock-based definition of default whereby shareholders inject funds in the firm as long as equity value is positive (as in Leland, 1994; Mello and Parsons, 1992; Morellec, 2001). This condition implies that shareholders default on their debt obligations the first time equity value is equal to zero. Denote by $\underline{X}_{j}(c)$ the default threshold selected by shareholders when operating cash flows are given by $\Pi_{j} X$ and the firm's coupon payment is $c$. In addition, let $E_{j}(X, c), j=o, m$, denote the value of a bidder's equity after the contest if he loses $(j=o)$ or wins $(j=m)$ the takeover contest. Proposition 1 specifies the values of a bidder's equity after the takeover depending on the success of its bid. (All proofs are gathered in the Appendix).

Proposition 1. The equity value of bidder $j$ after the takeover contest is given by

$$
E_{j}(X, c)=(1-\tau)\left[\frac{\Pi_{j} X}{r-\mu}-\frac{c}{r}+\frac{c}{r(1-v)}\left(\frac{X}{\underline{X}_{j}(c)}\right)^{v}\right], \quad j=o, m,
$$

where the selected default threshold $\underline{X}_{j}(c)$ satisfies

$$
\underline{X}_{j}(c)=\frac{v}{v-1} \frac{c(r-\mu)}{\Pi_{j} r}, \quad j=o, m,
$$

and $v$ is the negative root of the quadratic equation $\frac{1}{2} \sigma^{2} y(y-1)+\mu y-r=0$.

In Eq. (3), the first two terms in the square brackets represent the value of a perpetual entitlement to the current flow of income, given by $(1-\tau)\left(\Pi_{j} X-c\right)$. The last term is the value of shareholders' option to default, which is the product of the surplus created by this option and a stochastic discount factor, given by $X^{v} \underline{X}_{j}^{-v}$. The selected default threshold in Eq. (4) takes the usual functional form and has the following properties. The higher the coupon payment, the lower the growth rate of the industry shock $X$, and the lower its volatility, the higher the optimal default threshold. Low growth rate and low volatility of the demand shock imply a low

\footnotetext{
${ }^{3}$ In our model, this reduction in cash flow is not related to the bidding process itself. Instead, it is imposed on the losing bidder by a change in the industry structure because of the restructuring. This assumption does not drive our results. Qualitatively similar conclusions are obtained when $\Pi_{o}=\Pi_{b}$. Fig. 3 illustrates the impact of $\Pi_{o}$ on equilibrium financing strategies.
} 
option value of waiting to default. The default threshold also increases with the discount rate $r$. When the discount rate is high, stockholders are more concerned about immediate losses than about potential future profits. As a result, they exercise their default option sooner.

Suppose that one firm places a bid to acquire the target. The other bidder can either place a higher bid or lose the contest. As long as it is better off outbidding the first bidder, the second bidder has an incentive to place a higher bid, so that the first bidder loses the contest and becomes the outsider. The same logic makes the first bidder place a new bid to outbid the second one. Bidding continues up to the point where one of the bidders becomes better off losing the takeover contest. Call the value of the bid at that point the bidder's reservation value. The above argument reveals that the bidder with the lower reservation value loses the takeover contest. As we show below, the reservation value is a function of the bidder's leverage ratio. Therefore, capital structure plays an important role in determining the outcome of the takeover contest.

The maximum price that a bidder is willing to pay to acquire the target follows from Proposition 1 and is given by the difference between the equity value of the merged entity and the equity value of a losing bidder:

$$
\Delta E\left(X, c_{i, b}\right)=(1-\tau)\left[\frac{X\left(\Pi_{m}-\Pi_{o}\right)}{r-\mu}-\frac{c_{\mathrm{tar}}}{r}+\frac{X^{v}}{r(1-v)}\left(\frac{c_{i, b}+c_{\mathrm{tar}}}{\left(\underline{X}_{m}\left(c_{i, m}\right)\right)^{v}}-\frac{c_{i, b}}{\left(\underline{X}_{o}\left(c_{i, b}\right)\right)^{v}}\right)\right] .
$$

Bidder $i$ is indifferent between paying $\Delta E\left(X, c_{i, b}\right)$ to acquire the target or losing the takeover contest. In other words, $\Delta E\left(X, c_{i, b}\right)$ is the reservation value discussed above. Because the two bidders could have different financing strategies, in general they are willing to offer different premiums for the acquisition transaction. Proposition 2 establishes some key properties of the maximum price that a bidding firm is willing to pay to acquire the target.

Proposition 2. The maximum price that a bidding firm is willing to pay to acquire the target, $\Delta E\left(X, c_{i, b}\right)$, decreases with the bidder's contractual coupon $c_{i, b}$ and increases with the value of the industry shock $X$ (the state of the industry).

Now let $c_{1, b}$ and $c_{2, b}$ be the coupon payments of the two bidders. Furthermore, let $c_{1, b}>c_{2, b}$. Then the Nash equilibrium in bidding strategies is for the bidder with the higher coupon (bidder 1) to quote $\Delta E\left(X, c_{1, b}\right)$ and for the other bidder to quote an offer price $P>\Delta E\left(X, c_{1, b}\right){ }^{4}$ Assume that the target firm can achieve a fraction $\eta \in[0,1]$ of the difference between the reservation value of bidder 2 and the reservation value of bidder $1 .{ }^{5}$ In equilibrium, the optimal strategy for bidder 1 is to become an outsider. Bidder 2 pays $\Delta E\left(X, c_{1, b}\right)+$ $\eta\left[\Delta E\left(X, c_{2, b}\right)-\Delta E\left(X, c_{1, b}\right)\right]$ to target shareholders and wins the contest. This follows from the fact that if the acquisition price is equal to $\Delta E\left(X, c_{2, b}\right)$, bidder 2 is indifferent between winning the takeover contest and becoming an outsider, and from the monotonicity of $\Delta E(X, c)$ established in Proposition 2.

The economic intuition underlying these equilibrium bidding strategies is as follows. By acquiring the target, bidding shareholders increase not only the value of the firm's assets but also the value of outstanding bonds by decreasing the probability of default. That is, part of the takeover surplus is captured by the debtholders of the bidding firm. Because the wealth transfer between shareholders and bondholders increases with leverage, the net benefit of the control transaction to the shareholders of the bidding firm decreases with leverage. This makes the maximum acquisition price a decreasing function of leverage. Importantly, any tender offer below $\Delta E\left(X, c_{1, b}\right)$ cannot be part of an equilibrium strategy. The bidder that places this bid loses the takeover contest, because the other firm has an incentive to outbid and win. Proposition 3 follows.

\section{Proposition 3. When $c_{1, b}>c_{2, b}$, bidder 2 wins the takeover contest and pays a price $\Delta E\left(X, c_{1, b}\right)+$ $\eta\left[\Delta E\left(X, c_{2, b}\right)-\Delta E\left(X, c_{1, b}\right)\right]$. Bidder 1 loses the takeover contest.}

\footnotetext{
${ }^{4}$ In our model, targets are scarce and competition between multiple bidders hurts the acquirer. See Bradley, Desai, and Kim (1988) and De, Fedenia, and Triantis (1996) for evidence supporting this view.

${ }^{5}$ When $\eta=0$, the outcome of the takeover contest is determined through an ascending English auction. In our model, $\eta$ has two opposite effects on the financing strategies of bidding firms. First, for a given timing of the takeover, an increase in $\eta$ leads to a decrease in the value of the takeover opportunity and, hence, in the dispersion of leverage ratios. Second, an increase in $\eta$ fastens the takeover process leading to an increase in the value of the takeover opportunity. In our base case environment, the first effect dominates, so that an increase in $\eta$ leads to a decrease in the dispersion of leverage ratios. We thank the referee for suggesting the use of a sharing rule $\eta>0$.
} 


\subsection{Timing and terms of the takeover}

Consider next the timing of the takeover. Suppose that target shareholders have perfect information about the industry shock and about the financing strategies of bidding firms. The objective of target shareholders is to maximize the acquisition premium net of the costs associated with the control transaction. In the analysis below, we assume that target shareholders announce the minimum acquisition price $I$, for which they are willing to surrender the control of their firm. Because $\Delta E(X, c)$ increases with the value of the industry shock $X$ for any coupon payment $c$, the equilibrium takeover price $\Delta E\left(\bar{X}, c_{1, b}\right)+\eta\left[\Delta E\left(\bar{X}, c_{2, b}\right)-\Delta E\left(\bar{X}, c_{1, b}\right)\right]$ increases with $X$ for any pair $\left(c_{1, b}, c_{2, b}\right)$. This implies that there is a unique mapping from $X$ to $I$. Therefore, selecting the selling price is equivalent to selecting the value of the industry shock at which the transaction occurs and hence the timing of the takeover. In particular, because of the monotonicity of $\Delta E(X, c)$, the takeover contest takes place the first time that $X$ reaches the threshold $\bar{X}$, determined by the following condition:

$$
\bar{X}: \Delta E\left(\bar{X}, c_{1, b}\right)+\eta\left[\Delta E\left(\bar{X}, c_{2, b}\right)-\Delta E\left(\bar{X}, c_{1, b}\right)\right]=I, \quad \eta \in[0,1] .
$$

Once the threshold $\bar{X}$ is reached, bidder 2 acquires the target by paying $I$. Bidder 1 has no incentive to outbid and therefore loses the takeover contest and becomes an outsider. As long as Eq. (6) holds, selecting the threshold $\bar{X}$ is equivalent to selecting the selling price $I$. Thereafter, we thus assume that target shareholders choose the takeover threshold $\bar{X}$ to maximize the value of their claims.

Takeovers typically impose costs on target shareholders (related, for example, to the loss of private benefits of control). In the analysis below, we consider that target shareholders bear a cost $K$ at the time of the takeover. When choosing the selling price of their firm, target shareholders seek to maximize the present value of the takeover premium net of the costs associated with the control transaction. In our model, these costs include not only the direct cost $K$ but also the opportunity cost of waiting associated with the possibility of foreclosure. Specifically, because the bidding and target firms are partially financed with risky debt, one of these firms could go bankrupt before a takeover occurs. In the following analysis, we assume that antitrust authorities would then prevent the two remaining firms from merging and forming a monopoly. ${ }^{6}$ Therefore, if one of the bidding firms forecloses, no takeover is feasible. This imposes an additional cost of waiting on target shareholders.

Denote by $\underline{X}_{1}, \underline{X}_{2}$, and $\underline{X}_{\text {tar }}$ the default thresholds selected by bidder 1, bidder 2, and the target firm, respectively. Because no takeover is feasible if either one of the bidding firms or the target firm defaults on its debt obligations, a takeover can occur only if the industry shock reaches the takeover threshold $\bar{X}$ before reaching the highest of the three default thresholds $\underline{X}_{1}, \underline{X}_{2}$, and $\underline{X}_{\operatorname{tar}}$. Because bidding firms have the same cash flow structure and $c_{1, b}>c_{2, b}$, it must be that $\underline{X}_{1}>\underline{X}_{2}$. In addition, we also know that the decision to default balances the value of equity in continuation (which is higher for the target firm because of the benefits of the takeover) with the value of equity in default (which is the same for both firms). As a result, it must also be that $\underline{X}_{1}>\underline{X}_{\operatorname{tar}}$. The above reasoning implies that takeovers arise only if $X$ reaches $\bar{X}$ before reaching $\underline{X}_{1}$.

Assume that $X_{0} \in\left(\underline{X}_{1}, \bar{X}\right)$. Denote by $\mathscr{L}(X ; z, y)$ the present value of $\$ 1$ to be received the first time $X$ reaches the lower threshold $z$, conditional on $X$ reaching $z$ before reaching the upper threshold $y$. In addition, denote by $\mathscr{H}(X ; z, y)$ the present value of one dollar to be received the first time that the industry shock $X$ reaches the higher threshold $y$, conditional on $X$ reaching $y$ before the lower threshold $z$. We then have Proposition 4.

Proposition 4. The value-maximizing strategy for target shareholders is to sell their firm at the price $I=(1-\eta) \Delta E\left(\bar{X}, c_{1, b}\right)+\eta \Delta E\left(\bar{X}, c_{2, b}\right)$, where the takeover threshold $\bar{X}$ is the solution to the following maximization problem:

$$
\bar{X}=\underset{y}{\arg \max }\left\{(1-\tau) \mathscr{L}\left(X ; \underline{X}_{1}, y\right)\left(\frac{\underline{X}_{1}}{\underline{X}_{\operatorname{tar}}}\right)^{v} \frac{c_{\operatorname{tar}}}{r(1-v)}+\mathscr{H}\left(X ; \underline{X}_{1}, y\right) F(y)\right\}
$$

\footnotetext{
${ }^{6}$ Even if the antitrust authorities do not preclude the takeover, the foreclosure of a given bidder reduces competition for the target firm. This lowers the acquisition premium accrued to the target and makes the takeover less attractive from the target's perspective.
} 
with

$$
F(y)=(1-\eta) \Delta E\left(y, c_{1, b}\right)+\eta \Delta E\left(y, c_{2, b}\right)-\left[K+(1-\tau)\left(\frac{\Pi_{\operatorname{tar}} y}{r-\mu}-\frac{c_{\operatorname{tar}}}{r}\right)\right] .
$$

In this equation, $\underline{X}_{1}$ is the default threshold selected by the shareholders of the unsuccessful bidding firm (firm 1), $\underline{X}_{\operatorname{tar}}$ is the default threshold selected by target shareholders defined by

$$
\underline{X}_{\mathrm{tar}}=\frac{v}{v-1} \frac{c_{\mathrm{tar}}(r-\mu)}{\Pi_{\mathrm{tar}} r}
$$

and the quantities $L(X ; z, y)$ and $H(X ; z, y)$ are defined by

$$
\begin{aligned}
& \mathscr{L}(X ; z, y)=\left(y^{\xi} X^{v}-y^{v} X^{\xi}\right)\left(y^{\xi} z^{v}-y^{v} z^{\xi}\right)^{-1}, \\
& \mathscr{H}(X ; z, y)=\left(X^{\xi} z^{v}-X^{v} z^{\xi}\right)\left(y^{\xi} z^{v}-y^{v} z^{\xi}\right)^{-1},
\end{aligned}
$$

where $\xi$ and $v$ are, respectively, the positive and negative roots of the quadratic equation $\frac{1}{2} \sigma^{2} y$ $(y-1)+\mu y-r=0$. Under this strategy, the takeover occurs the first time the industry shock reaches $\bar{X}$, conditional on $X$ reaching $\bar{X}$ before $\underline{X}_{1}$.

The objective function in Eq. (7) has two components. The first term in the curly brackets accounts for the impact of the takeover threshold on the option to default of target shareholders. This option to default is the product of two terms: the payoff of the option in default $\left((1-\tau) c_{\mathrm{tar}} /[r(1-v)]\right)$ and a stochastic discount factor $\left(\mathscr{L}\left(X ; \underline{X}_{1}, \bar{X}\right) \underline{X}_{1}^{v} \underline{X}_{\operatorname{tar}}^{-v}\right)$ that represents the present value of $\$ 1$ to be received at the time of default. Importantly, once bidder 1 has defaulted, takeovers are precluded and the default threshold selected by target shareholders takes the usual functional form given by Eq. (9). The second term in the objective function can be decomposed as the takeover premium net of the control cost multiplied by an appropriate discount factor, given by Eq. (11). Proposition 5 establishes the existence of the solution to the maximization problem Eq. (7).

Proposition 5. For sufficiently large values of $K$, there exists a unique solution to the maximization problem of target shareholders defined in equation (7).

Fig. 1 represents the takeover trigger $\bar{X}$ that determines the selling price of the target firm as a function of the control cost $K$. In this figure, we consider that the abandonment value of the firm, denoted by $A_{j}(X)$, is equal to the unlevered value of the firm's assets, net of a proportional default costs $\alpha$ (a similar specification is

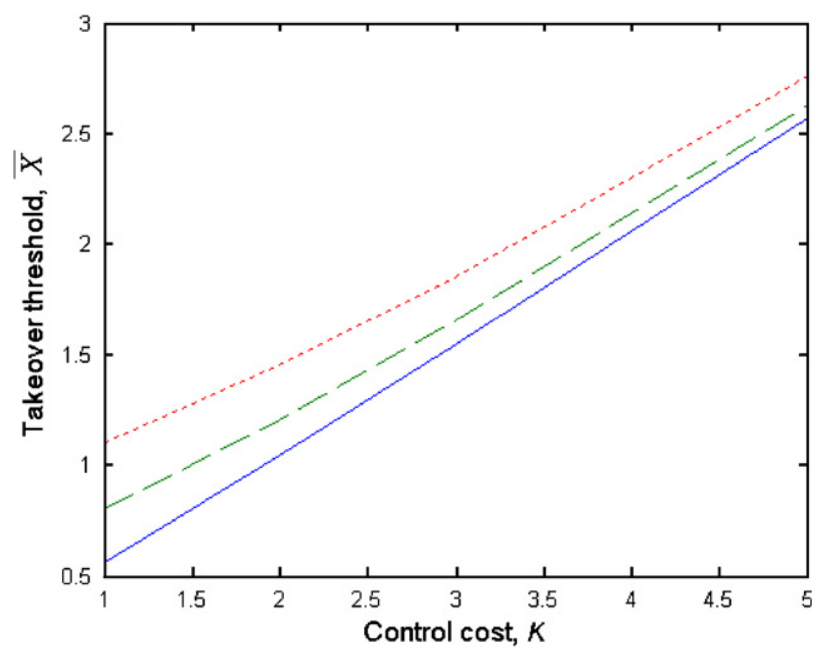

Fig. 1. Optimal takeover threshold. The figure plots the selected takeover threshold $\bar{X}$ as a function of the control cost, $K$. Parameter values are set as in the base case environment. The solid, dashed, and dotted lines correspond to the following values of the coupon payment: $c_{i, b}=0.1,0.6$, and 1.0 . 
used in Mello and Parsons, 1992; Leland, 1994):

$$
A_{j}(X)=(1-\alpha)(1-\tau) \frac{\Pi_{j} X}{r-\mu}, \quad \text { for } j=b, o, m .
$$

In addition, we use the following input parameter values: $r=0.06, \mu=0.01, \sigma=0.25, \Lambda /\left(\Pi_{i, b}+\Pi_{\mathrm{tar}}\right)=0.10$, $\tau=0.15, \eta=0.5$, and $\alpha=0.4$. The risk-free rate is taken from the yield curve on Treasury bonds. The growth rate of cash flows has been selected to generate a dividend yield consistent with observed yields (see Ibbotson Associates, 2002). Similarly, the value of the volatility parameter has been chosen to match the (leverageadjusted) asset return volatility of an average Standard and Poor's (S\&P) 500 firm's (see Strebulaev, 2007). The tax advantage of debt captures corporate and personal taxes and is set equal to $\tau=0.15$. Liquidation costs are defined as the firm's going concern value minus its liquidation value, divided by its going concern value (measured by $1-\alpha$ in our model). Using this definition, Alderson and Betker (1995) and Gilson (1997), respectively, report liquidation costs equal to $36.5 \%$ and $45.5 \%$ for the median firm in their samples. Finally, Healey, Palepu, and Ruback (1992) show a 14\% increase in the cash flows of the merged firms in their sample in the first year following a merger.

Fig. 1 reveals that the takeover threshold increases with the control cost $K$. As $K$ gets larger, target shareholders postpone the takeover, until the takeover premium is sufficiently high to compensate for the cost of the takeover. Fig. 1 also shows that the takeover threshold increases with the coupon payment of bidder 1 . In the present model, an increase in the coupon payment of bidder 1 reduces the equilibrium acquisition premium, leading to an increase in the option value of waiting for target shareholders. It also implies a higher probability of foreclosure, thereby providing an incentive for target shareholders to speed up the takeover. Fig. 1 shows that first effect dominates in the base case environment.

\subsection{Equilibrium financing strategies}

In this subsection, we examine the impact of the takeover contest on the equilibrium financing policies of bidding firms. We assume that firms select their coupon payments at time 0 and that debtholders have full information and rational expectations about the outcome of the takeover contest. This implies that they can assess the impact of debt financing on the timing and terms of the takeover. This also implies that they are able to identify the winner of the takeover contest, based on the debt levels of the firms in the industry. In equilibrium, they price their claims accordingly.

Assume that there exists an asymmetric equilibrium in leverage strategies and that the two bidders set their coupons equal to $c_{1, b}$ and $c_{2, b}$ with $c_{1, b}>c_{2, b}$. As established in Proposition 2, the firm with the lower coupon (bidder 2) then acquires the target. Prior to the takeover, the debt contract of the losing bidder (bidder 1) delivers a cash flow $c_{1, b}$ and its equity contract delivers a cash flow $(1-\tau)\left[\Pi_{b} X-c_{1, b}\right]$. The debt and equity values of bidder 1 can then be characterized as in Proposition 6.

Proposition 6. The debt and equity values of bidder 1 before the takeover satisfy:

$$
D_{1, b}(X)=\frac{c_{1, b}}{r}+\mathscr{L}\left(X ; \bar{X}, \underline{X}_{1}\right)\left[A_{b}\left(\underline{X}_{1}\right)-\frac{c_{1, b}}{r}\right]+\mathscr{H}\left(X ; \underline{X}_{1}, \bar{X}\right)\left(\frac{\bar{X}}{\underline{X}_{o}}\right)^{v}\left[A_{o}\left(\underline{X}_{o}\right)-\frac{c_{1, b}}{r}\right]
$$

and

$$
\begin{aligned}
E_{1, b}(X)= & (1-\tau)\left[\frac{\Pi_{b} X}{r-\mu}-\frac{c_{1, b}}{r}+\mathscr{H}\left(X ; \underline{X}_{1}, \bar{X}\right) \frac{\left(\Pi_{o}-\Pi_{b}\right) \bar{X}}{r-\mu}\right] \\
& +(1-\tau)\left[\mathscr{L}\left(X ; \bar{X}, \underline{X}_{1}\right)\left(\frac{c_{1, b}}{r}-\frac{\Pi_{b} \underline{X}_{1}}{r-\mu}\right)+\mathscr{H}\left(X ; \underline{X}_{1}, \bar{X}\right)\left(\frac{\bar{X}}{\underline{X}_{o}}\right)^{v} \frac{c_{1, b}}{r(1-v)}\right]
\end{aligned}
$$

where $L(X ; z, y)$ and $H(X ; z, y)$ are defined in Eqs. (10) and (11), $\underline{X}_{1}$ is the default threshold of bidder 1 , and $A_{j}(x)$ is the abandonment value of the firm's assets. 
Proposition 6 shows that the equity value of the losing bidder has three components. The first two terms in the square brackets represent the present value of a perpetual entitlement to the current flow of income (ignoring the options available to the firm) assuming that the firm operates forever within the same industry structure. The third term in the square brackets represents the change in the value of equity resulting from a potential control transaction. Finally, the last term on the right-hand side of Eq. (14) represents the value of the option to default. In our model, this option value has two components because default can occur either before or after the takeover. The value of debt in Proposition 6 has two components: the value of perpetual coupon payments and the expected loss net of recovery value realized in the event of default (which depends on whether a takeover occurs before or after default).

The next step in identifying equilibrium financing strategies is to determine the value of bidder 2's securities as a function of its coupon payment under the assumption that bidder 2 takes the financing and default strategies of bidder 1 and the corresponding takeover timing as given. These values are given in Proposition 7.

Proposition 7. The debt and equity values of bidder 2 before the takeover are given by

$$
D_{2, b}(X)=\frac{c_{2, b}}{r}+\mathscr{L}\left(X ; \underline{X}_{1}, \bar{X}\right)\left(\frac{\underline{X}_{1}}{\underline{X}_{2}}\right)^{v}\left[A_{b}\left(\underline{X}_{2}\right)-\frac{c_{2, b}}{r}\right]+\mathscr{H}\left(X ; \underline{X}_{1}, \bar{X}\right)\left(\frac{\bar{X}}{\underline{X}_{m}}\right)^{v}\left[\frac{c_{2, b}}{c_{2, b}+c_{\mathrm{tar}}} A_{m}\left(\underline{X}_{m}\right)-\frac{c_{2, b}}{r}\right]
$$

and

$$
\begin{aligned}
E_{2, b}(X)= & (1-\tau)\left[\frac{\Pi_{b} X}{r-\mu}-\frac{c_{2, b}}{r}+\mathscr{L}\left(X ; \underline{X}_{1}, \bar{X}\right) \frac{c_{2, b}}{r(1-v)}\left(\underline{\underline{X}}_{1}\right)^{v}\right] \\
& +\mathscr{H}\left(X ; \underline{X}_{1}, \bar{X}\right)\left\{(1-\tau)\left[\frac{\Pi_{\mathrm{tar}}+\Lambda}{r-\mu} \bar{X}-\frac{c_{\mathrm{tar}}}{r}+\frac{c_{2, m}}{r(1-v)}\left(\frac{\bar{X}}{\underline{X}_{m}}\right)^{v}\right]-I\right\},
\end{aligned}
$$

where $c_{2, m}=c_{2, b}+c_{\mathrm{tar}}, A_{j}(x)$ is the abandonment value of the firm, and $\underline{X}_{2}$ and $\underline{X}_{m}$ are the equity valuemaximizing default thresholds of bidder 2 before and after the takeover, respectively:

$$
\underline{X}_{2}=\frac{v}{v-1} \frac{c_{2, b}(r-\mu)}{\Pi_{b} r} \text { and } \underline{X}_{m}=\frac{v}{v-1} \frac{c_{2, m}(r-\mu)}{\Pi_{m} r} .
$$

Proposition 7 shows that equity value of the winning bidder has three components. The first two terms in the square brackets represent the expected present value of the cash flows accruing to shareholders if the firm operates forever within the same industry structure and the value of the option to default before the takeover (last term in the square brackets). The last term represents the change in the present value of cash flows following a control transaction. In this expression, the change in the value of equity resulting from a potential control transaction is multiplied by a stochastic discount factor $\mathscr{H}\left(X ; \underline{X}_{1}, \bar{X}\right)$. This stochastic discount factor represents the value of $\$ 1$ to be received at the time of the takeover and captures the state-contingent nature of the model. The value of debt in Proposition 7 has two components: the value of perpetual coupon payments and the expected loss net of recovery value realized in the event of default. Following a control transaction, shareholders of the acquiring firm assume the debt obligations of the target. In the event of foreclosure, the firm defaults on both debt contracts. Assuming equal seniority, debtholders split the abandonment value of the firm on a pro rata basis.

In equilibrium, the takeover and default thresholds $\bar{X}$ and $\underline{X}_{1}$ as well as the coupon payments $c_{1, b}$ and $c_{2, b}$ are endogenous. Given any triple $\left(\underline{X}_{1}, c_{1, b}, c_{2, b}\right)$, target shareholders select the timing of the takeover (by choosing the selling price $I$ ) to maximize the expected discounted takeover premium net of the control costs. Given $\bar{X}$, shareholders of the losing bidder (bidder 1) select their financing policy $c_{1, b}$ and the default threshold $\underline{X}_{1}$ to maximize the value of their claims.

The final element in the equilibrium is the coupon payment of bidder $2, c_{2, b}$. When selecting their financial strategy, shareholders seek to maximize the sum of equity value after debt has been issued and the proceeds from debt issue. However, because of the impact of financing on the outcome of the takeover contest, bidder 2 cannot formulate its financing strategy in isolation, without regard to the potential impact on the other bidder's financing strategy. First, if $c_{2, b}>c_{1, b}$, the roles of the two firms switches and bidder 2 loses its strategic 
advantage over bidder 1 . Second, because at the time of debt issuance the two firms are free to choose their leverage, it must be that the benefits of leverage for the two firms coincide. In particular, if bidder 2 selected a coupon that allowed it to reach a value higher than that of bidder 1, the latter would have an incentive to issue debt with a coupon just marginally below that of bidder 2 . The incentive to undercut bidder 2 in leverage disappears once the total benefits of debt financing are the same for the two bidders. Bidder 2 enjoys the benefit of winning the takeover contest. But at the same time, it does not fully utilize the tax benefits of debt. At the equilibrium point, the increase in value stemming from takeover is fully offset by the lower tax shields resulting from the lower leverage ratio.

The two bidders never choose the same leverage ratio in equilibrium. In such a scenario, the stockholders of a bidding firm would be indifferent ex-post between acquiring the target and losing the takeover contest (all the benefits of the takeover accrue to the target). However, at the time of the debt issue, the value of corporate debt is affected by the future outcome of the takeover contest. In particular, if a firm can commit to win the contest, the total value of its securities increases because operational performance improves following the takeover (leading to lower probability of default and to higher debt values). In our model the firm's financing strategy plays the role of such a commitment device. As long as the total value of bidder 2 (the winner) is above that of bidder 1, the two firms have an incentive to undercut each other in leverage. Therefore in a symmetric equilibrium both firms must have zero leverage. But as long as the corporate tax rate $\tau$ is positive, a bidder always has an incentive to issue debt. Therefore, no symmetric equilibrium exists. The logic of the equilibrium is formalized by the Proposition 8.

Proposition 8. The equilibrium values of the acquisition and default thresholds $\bar{X}$ and $\underline{X}_{1}$ maximize the objective function in the optimization problem of target shareholders given in Eq. (7) and the value of the shares of bidder 1 given in Eq. (14). In addition, the coupon payments $c_{1, b}^{*}$ and $c_{2, b}^{*}$ are jointly determined by the following system of equations:

$$
c_{1, b}^{*}=\arg \max \left[E_{1, b}\left(X, c_{1, b}\right)+D_{1, b}\left(X, c_{1, b}\right)\right]
$$

and

$$
v_{1, b}\left(X, c_{1, b}^{*}\right)-E_{1, b}(X, 0)=v_{2, b}\left(X, c_{2, b}^{*}\right)-E_{2, b}(X, 0),
$$

where $v_{i, b}\left(X, c_{i, b}^{*}\right)=E_{i, b}\left(X, c_{i, b}^{*}\right)+D_{i, b}\left(X, c_{i, b}^{*}\right)$ is the value of bidder $i$ for a given industry shock $X$ and a given coupon payment $c_{i, b}^{*}$.

Fig. 2 presents the total value of bidder 2 as a function of its coupon payment in our base case environment. The values displayed in Fig. 2 are conditional on the assumption that bidder 2 wins the takeover contest and bidder 1 does not attempt to undercut bidder 2 in leverage. The maximum feasible value of bidder 1 is shown for reference purposes. In this figure, value functions are defined for $c_{2, b}<c_{1, b}^{*}=0.49$.

Fig. 2 shows that the equilibrium coupon of the winning bidder, $c_{2, b}^{*}$, is equal to 0.21 in the base case environment. For any $c_{2, b}<0.21$, the value of bidder 1 exceeds that of bidder 2 . Hence, bidder 2 has an incentive to raise its coupon payment. By doing so, it is able to increase the total value of its securities without bringing about any strategic implications on the part of bidder 1 . Therefore, any value of $c_{2, b}$ below 0.21 cannot be the equilibrium coupon payment. Likewise, any $c_{2, b}>0.21$ cannot be the equilibrium coupon payment, as in this region bidder 1 always has an incentive to undercut bidder 2 in leverage to win the contest and increase its value. Thus, $c_{2, b}=0.21$ is the equilibrium coupon of bidder 2 . If bidder 2 could win the takeover contest regardless of its financing strategy (or if it was the only bidder), then its coupon payment would be 0.61. It follows that the strategic role of debt reduces the selected coupon payment by more than $65 \%$.

This analysis shows that, because of the impact of debt financing on the outcome of takeover contests, a firm selects a leverage ratio that is substantially lower than the leverage ratio implied by models of capital structure in which investment policy is fixed. The model also helps explain why otherwise identical firms could choose to have very different leverage ratios. In our asymmetric equilibrium one firm decides to have a lower leverage ratio to receive some of the NPV of the investment (takeover) opportunity. The other firm makes up for the loss of the growth opportunity by selecting a higher debt level and thus by getting greater tax benefits. Therefore, in this model two ex-ante identical firms optimally choose asymmetric strategies. One becomes a 


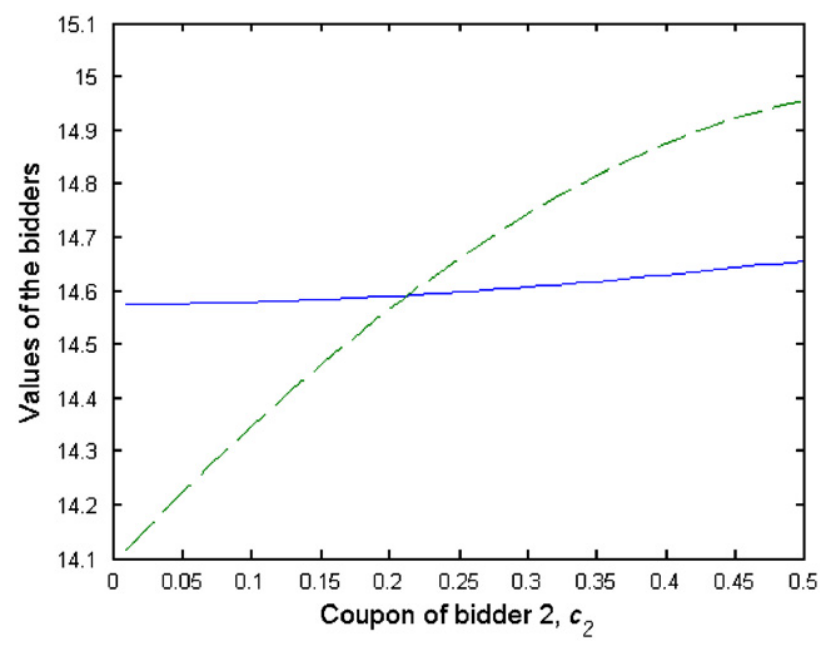

Fig. 2. Values of the bidding firms. The figure plots the value of the losing bidder (bidder 1, solid line) and the value of the winning bidder (bidder 2, dashed line) as the coupon of bidder 2 varies. Parameter values are set as in the base case environment.

growth firm, selects a low leverage ratio, and invests. The other becomes a value firm, selects a higher leverage ratio, and does not invest.

To get more insights into the determinants of financing policies, Fig. 3 plots the firms' leverage ratios for different values of the synergy benefits $\Lambda$, the volatility parameter $\sigma$, bankruptcy costs $\alpha$, corporate taxes $\tau$, the value of the industry shock $X$, and the operating cash flows of the losing bidder $\Pi_{o}$. As shown by the figure, the leverage ratio of the winning bidder (bidder 2) is substantially lower than that of the losing bidder (bidder 1). The figure also illustrates four predictions of the model.

First, the leverage ratio of bidder 2 decreases with $\Lambda$ and increases with $\Pi_{o}$. An increase in synergy benefits speeds up the takeover and therefore increases its strategic impact on the firms' financing strategies. This increases the takeover surplus and the leverage spread. By contrast, an increase in $\Pi_{o}$ reduces the cost of being the losing bidder and, hence, the leverage spread. Second, the optimal leverage ratios of both bidders decrease with volatility. An increase in volatility leads to an increase in the probability of default and thus in the cost of debt. In addition, since the value of the real option to do a takeover increases with volatility, so does the leverage gap between bidding firms. Third, the spread in leverage ratios increases with the value of the industry shock $X$. In other words, as the benefits associated with the takeover increase, the likelihood of a takeover increases and the strategic role of debt becomes more important. Fourth, the asymmetry in financing policies is greater in industries with low bankruptcy costs. Specifically, a decrease in bankruptcy costs leads to an increase in the benefits of the takeover and, therefore, to a greater asymmetry in leverage.

\subsubsection{Adjusting leverage after the takeover}

Suppose now that firms can change their financing policy immediately after the takeover. ${ }^{7}$ This timing for the capital structure rebalancing is not arbitrary. Once the takeover has taken place, debt loses its strategic role. Therefore the merged entity will naturally want to adjust its leverage ratio based on pure "tax benefits

\footnotetext{
${ }^{7}$ For the sake of tractability and analytical transparency, we assume as in other papers on capital structure and competition (e.g., Lambrecht, 2001; Miao, 2005) that the firm cannot change its coupon payment before the takeover. Relaxing this assumption and introducing dynamic capital structure strategies would present an interesting yet technically challenging extension. In that case analytical solution would be precluded, as one would have to find a fixed point in an infinite dimensional space to solve for the equilibrium. We believe that the static framework is realistic because of the transactions costs associated with issuing and retiring debt (in standard contingent claims models adjustments in debt policy are infrequent). The lower leveraged bidder still is able to offer a higher takeover premium, and the results are qualitatively similar to the static case. For dynamic capital structure strategies in a single firm framework, see, for example, Fischer, Heinkel, and Zechner (1989), Goldstein, Ju, and Leland (2001), Strebulaev (2007), or Hackbarth, Miao, and Morellec (2006).
} 
A

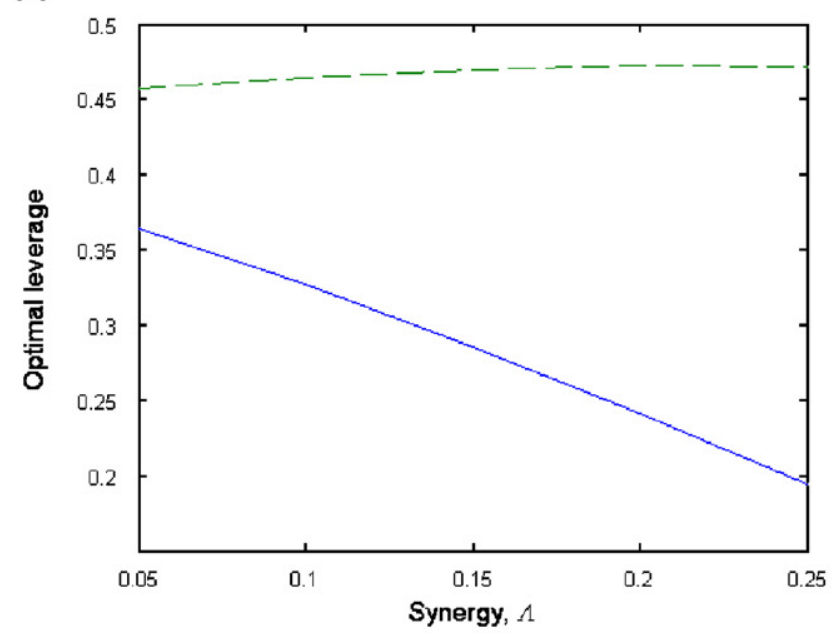

C

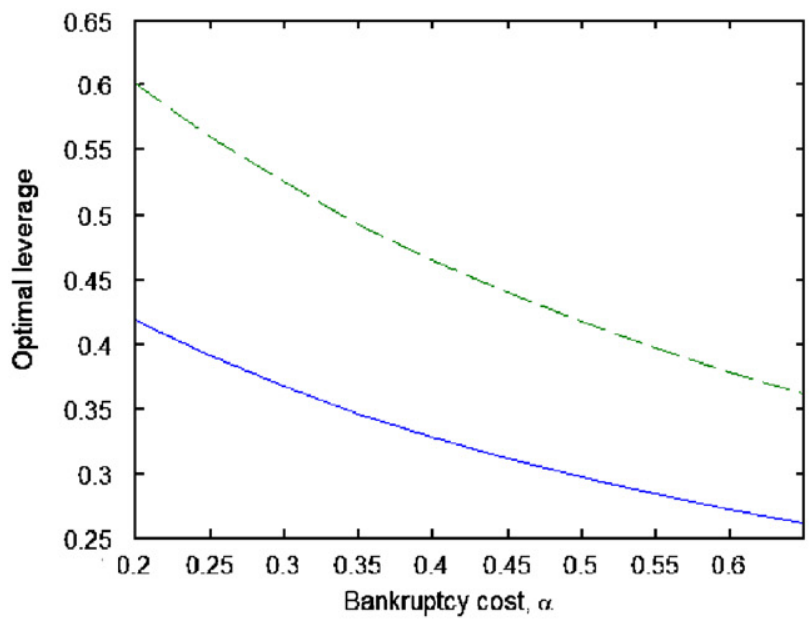

E

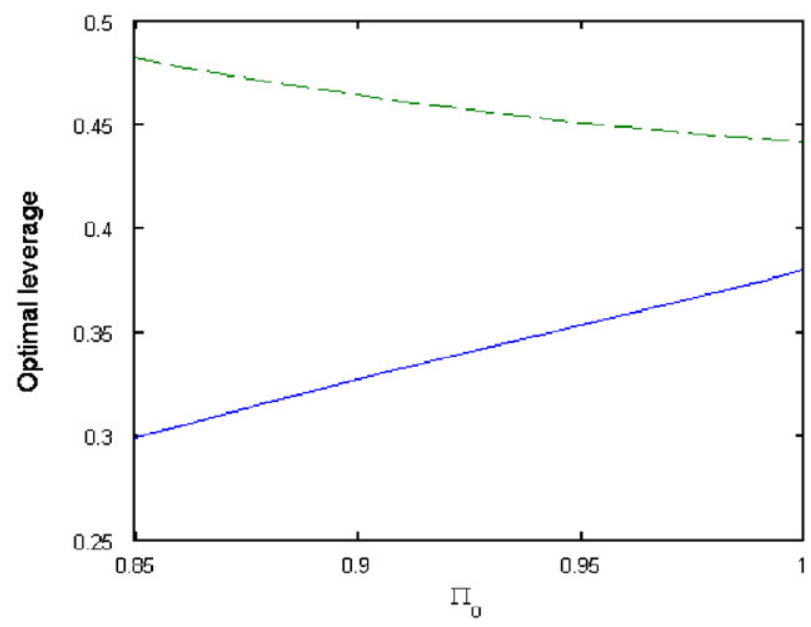

B

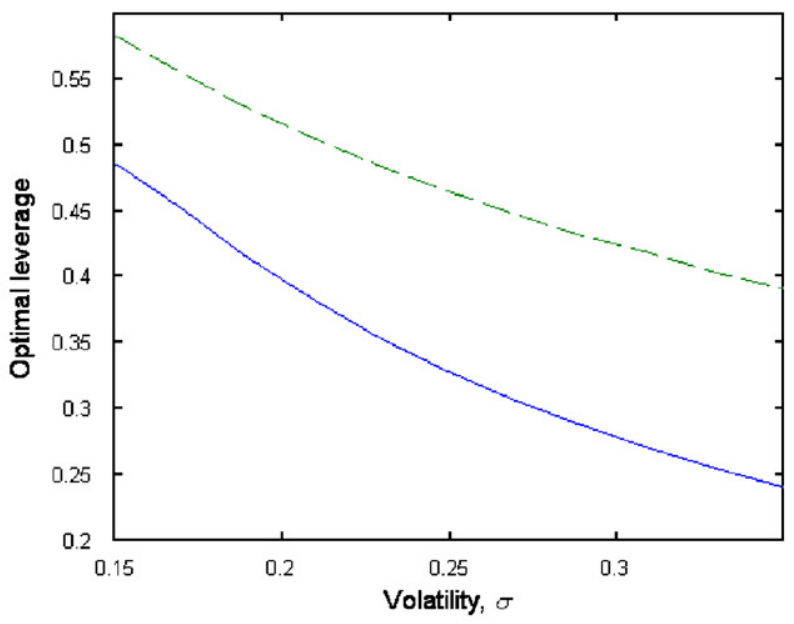

D

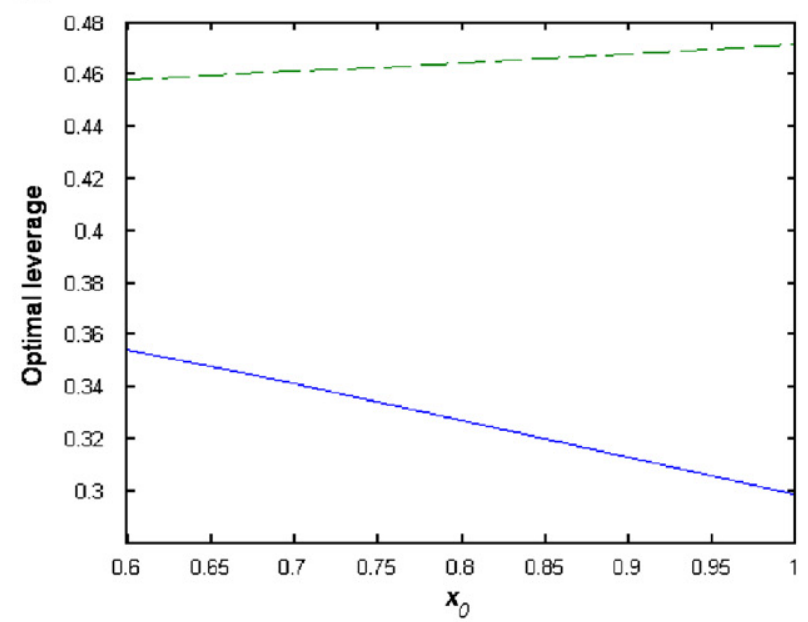

$\mathrm{F}$

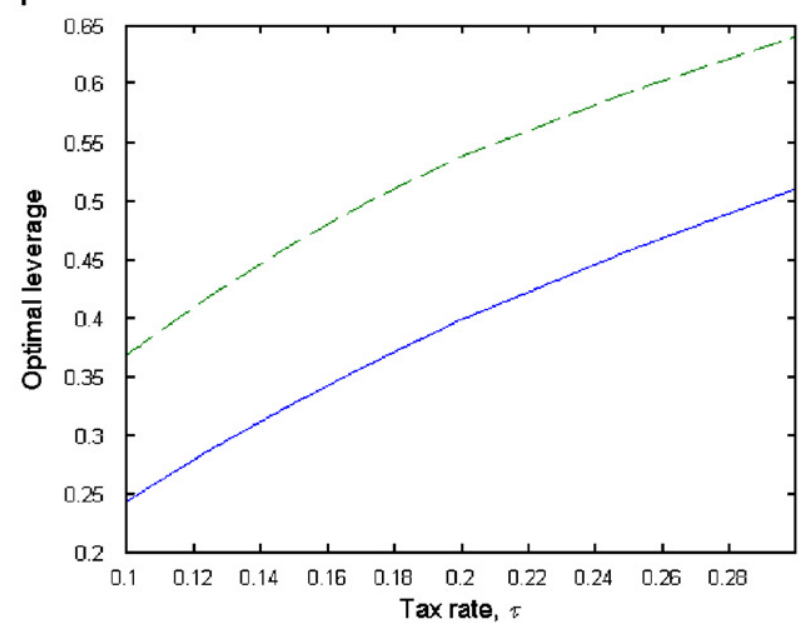

Fig. 3. Equilibrium leverage ratios. The figure illustrates the impact of the synergy parameter $\Lambda$, the volatility parameter $\sigma$, bankruptcy $\operatorname{costs} \alpha$, corporate taxes $\tau$, the operating cash flow of the losing bidder $\Pi_{o}$, and the initial state of the stochastic shock $x_{0}$ on equilibrium leverage ratios. The solid line represents the leverage ratio of bidder 2 , and the dashed line represents the leverage ratio of bidder 1 . Parameter values are set as in the base case environment. 


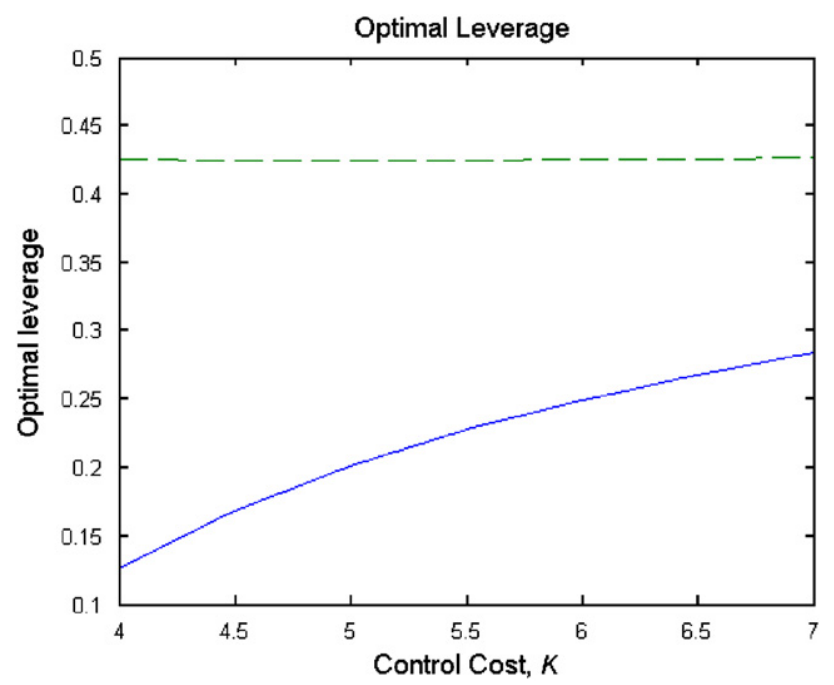

Fig. 4. Equilibrium leverage ratios of the bidders with debt restructuring. The figure plots the equilibrium initial leverage ratios of the bidders as functions of control cost, $K$, when debt restructuring is allowed immediately upon takeover consummation. The solid line represents the leverage ratio of bidder 2 , and the dashed line represents the leverage ratio of bidder 1 .

versus expected default costs" considerations. The new coupon $c_{2, m}^{*}$ is set to maximize the total value of equity at the time of restructuring, given by the value of new debt plus the ex-post value of equity:

$$
c_{2, m}^{*}=\underset{c}{\arg \max }\left[\Delta D_{2, m}\left(\bar{X}, c-c_{2, m}\right)+E_{2, m}(\bar{X}, c)\right] .
$$

In this equation, $\Delta D_{2, m}\left(\bar{X}, c-c_{2, m}\right)$ is the value of new debt issued by the merged entity. In equilibrium, claimholders take into account the implications of a change in leverage at the time of the takeover and adjust the price of their claims accordingly.

Fig. 4 plots the leverage ratios of the bidders as the control cost $K$ varies. Fig. 4 shows that allowing firms to change their leverage ratios after the takeover makes the equilibrium even more asymmetric. For example, for $K=4$ the ratio of bidder 1's to bidder 2's leverage is 3.23 , while in the static coupon case this ratio is equal to 1.81. This difference is a result of the value of the option to adjust leverage, which introduces an additional asymmetry in values in favor of the winning bidder. Debt loses its strategic role after the takeover contest and the merged entity has an incentive to lever up.

\subsubsection{Acquiring a highly levered target}

Suppose now that the target firm is highly levered relative to the bidder so that $c_{\operatorname{tar}} \Pi_{o}>c_{i, b}\left(\Pi_{m}-\Pi_{o}\right)$. For these transactions, a wealth transfer should take place from the claimholders of the bidding firm to target debtholders. That is, the target's debt becomes less risky and its value increases. At the same time, the bidder's debt becomes more risky and its value goes down. These effects imply that for such deals the acquisition premium increases with the leverage ratio of the bidding firm, so that the bidder with the higher leverage wins the takeover contest. In other words, equityholders expropriate existing bondholders by increasing the riskiness of their claims.

Importantly, we can still observe an asymmetric equilibrium in financing strategies when the target firm is highly levered. In this equilibrium, the bidder with the higher leverage wins the takeover contest. As a result, the value of its debt goes down. However, this bidder compensates the reduction in debt values by a greater tax benefit. By contrast, the bidder with the lower leverage loses the takeover contest and therefore has a more favorably priced debt, but it receives lower tax benefits. A symmetric equilibrium is still not feasible as long as there are tax benefits of debt. If competing bidders have the same coupon, then each of them has an incentive to marginally decrease its coupon so as to increase the (ex ante) value of its debt. 


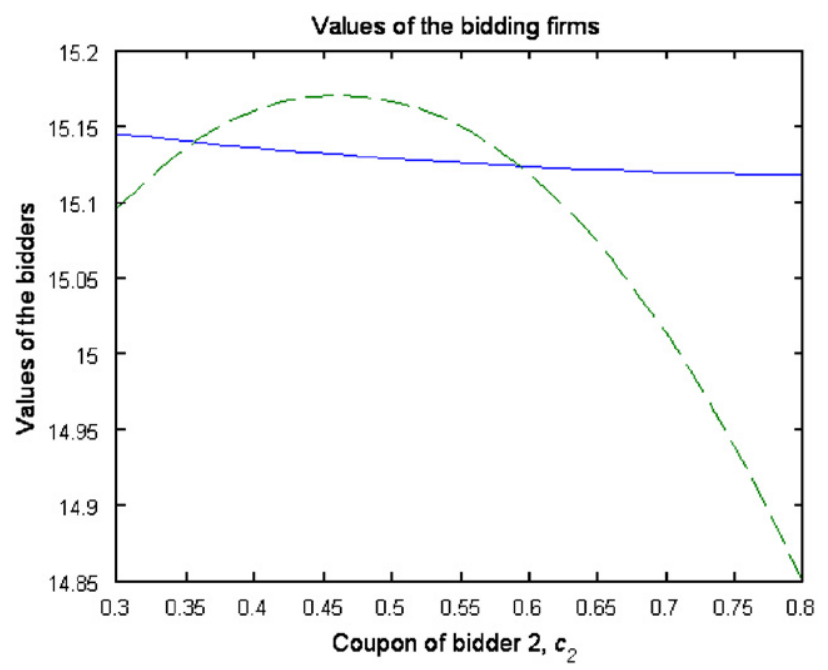

Fig. 5. Values of the bidding firms. The figure presents the values of the losing bidder (bidder 2) and the winning one (bidder 1) as functions of the coupon payment of bidder 2 in acquisitions involving highly levered targets. The equilibrium pair of coupon payments $\left(c_{1}, c_{2}\right)=(0.46,0.36)$. The solid line represents the total value of bidder 1 , and the dotted line represents the total value of bidder 2 . Parameter values are set as in the base case environment.

Fig. 5 illustrates this intuition by providing the values of the two bidding firms as the coupon payment of bidder 2 varies, under the assumption that bidder 2 accepts the role of the losing bidder. In this figure, the leverage ratio of the target firm is $84 \%$. Fig. 5 shows that, in this environment, the equilibrium coupon payment of bidder 2 (losing bidder) is 0.36 , while that of bidder 1 (winning bidder) is 0.46 . The corresponding leverage ratios are $37 \%$ and $46 \%$. While the unconditional value-maximizing leverage ratio of bidder 2 is $46 \%$, it is constrained to use less debt.

The above analysis shows that if there are no synergies, no spillover effect, and no coinsurance, then the acquisition premium increases with the leverage of the bidder as long as the bidder's leverage is below the target's one. Synergy gains lead to an increase in profitability and, hence, to an increase in the value of the bidder's debt. Coinsurance works in the same direction. Therefore even for considerably levered targets, the takeover transaction could still lead to an increase in the value of the bidder's debt so that the acquisition premium decreases in the bidder's leverage ratio.

Furthermore, because shareholders bear ex ante the cost of such leverage-increasing transactions, debt covenants would likely prohibit these transactions unless approved by current debtholders. For example, Chava, Kumar, and Warga (2005) report that over the period 2000-2003, 90\% of bond issues included covenants restricting the firm's ability to merge. Some of these bond issues allow mergers only if the net tangible assets of the firm, calculated on a post-merger basis, are at least a certain fraction of long-term debt. Such covenants would preclude acquisitions of highly levered targets and hence would prevent wealth transfers from bidding to target debtholders. As a result, we expect that such asymmetric equilibria in financing strategies would be precluded either because of bond covenants or because of merger synergies or coinsurance effects.

\section{Imperfect information}

In this section, we incorporate imperfect information into the model to show that the leverage spread should be related to the availability of information about merger synergies. Specifically, we consider an environment in which both bidders believe that the synergy benefit of the other bidder is uniformly distributed on the interval $\left[\Lambda_{i}-\varepsilon, \Lambda_{i}+\varepsilon\right]$, where $i=1,2$ and $\varepsilon>0$. Thus, while bidder $i$ knows the value of its synergy parameter $\Lambda_{i}$ with certainty, this value is not available to bidder $j$, who has information only about its distribution and 
considers $\Lambda_{i}$ as a random variable. Under this specification, beliefs are unbiased and the market's estimate of the synergy parameter of bidder $i$ coincides with its true value $\Lambda_{i}$.

Because the true synergy benefits are both equal to $\Lambda_{i}$, the bidder with the lower coupon wins the takeover contest, as in the case of perfect information. This is because no bidder has an incentive to raise its bid above the reservation value $\Delta E\left(X, c_{i, b}\right)$ given by Eq. (5), and $\Delta E\left(X, c_{i, b}\right)$ is a decreasing function of $c_{i, b}$, as established by Proposition 2. Even though at the start of the auction there is imperfect information regarding the synergy benefits, information about these synergy benefits is revealed during the bidding process. In particular, once a bidder leaves the takeover contest, its synergy parameter becomes known to the other bidder with certainty. That is, uncertainty is resolved through the bidding process.

At the time of debt issuance, the outcome of the takeover contest and the timing and terms of the takeover are uncertain, because the synergy profits are not known with certainty. Because of its impact on valuations, this uncertainty regarding the potential benefits of the takeover could also affect equilibrium financing strategies. Specifically, suppose that bidder 2's coupon is $c_{2, b}$. Then the best response of bidder 1 is to select the coupon payment $c_{1, b}^{*}\left(c_{2, b}\right)$ that maximizes the following quantity:

$$
V_{1, b}\left(c_{1, b}, c_{2, b}\right)=\mathbb{E}_{\Lambda}\left[E_{1, i}\left(c_{1, b}, c_{2, b}, \Lambda\right)+D_{1, i}\left(c_{1, b}, c_{2, b}, \Lambda\right)\right],
$$

where $i=o$ (respectively, $i=m$ ) if bidder 1 loses (respectively, wins) the takeover contest.

One essential difference between an environment with imperfect information and one with perfect information is that setting a coupon payment marginally below the coupon payment of the rival does not guarantee winning the takeover contest (as was the case with perfect information). Instead, it increases the probability of winning. Therefore, the marginal benefits of reducing the contractual coupon payment come in the form of the higher probability of winning the contest and lower expected bankruptcy costs, while the marginal costs are represented by the reduced tax savings.

When selecting their financing strategy, bidding shareholders trade off the marginal benefits of debt against its marginal costs. The nature of this trade-off depends on the magnitude of the uncertainty regarding synergy benefits. If there is little uncertainty, the benefits arising from the higher probability of winning the contest exceed the reduction in tax benefits. Therefore, bidding shareholders would like to reduce their coupon to the point where the subjective probability of winning is one. Fig. 6, Panel A, illustrates this logic by providing the best response function of both bidders when $\varepsilon=0.01$.

Fig. 6, Panel A, shows that when there is little uncertainty regarding the magnitude of synergy benefits, the best response curves of bidder 1 and bidder 2 do not intersect. Thus, whatever coupon payment a bidder

A

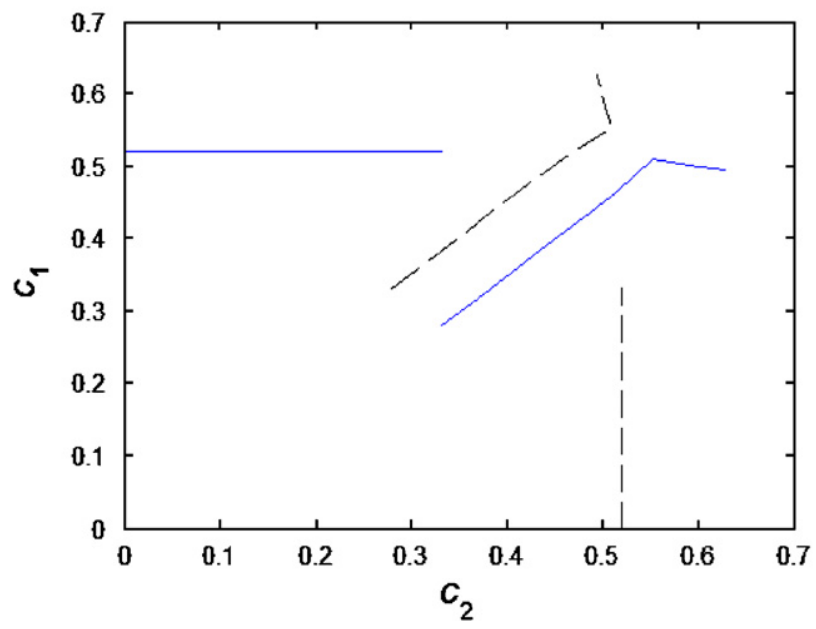

B

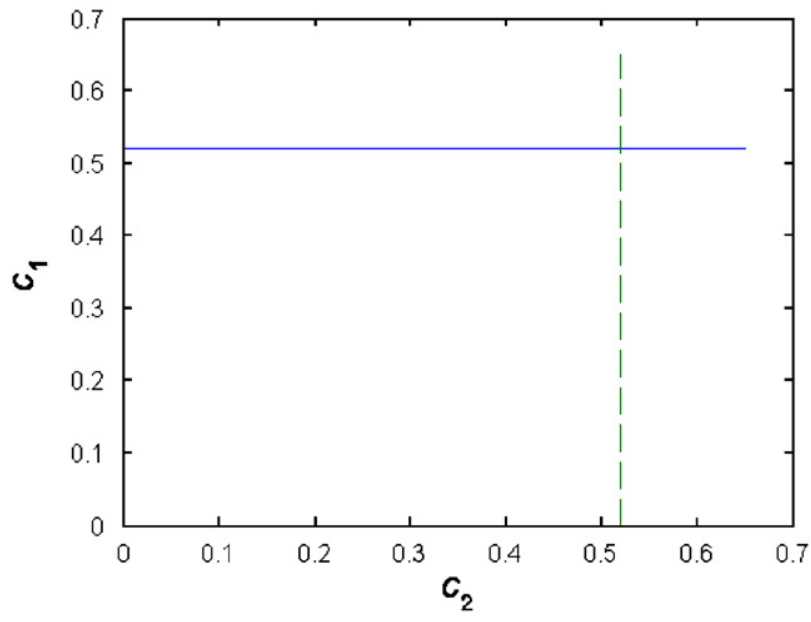

Fig. 6. Best response curves. The figure plots the optimal coupon of bidder 1 as a function of bidder 2's coupon for the case of imperfect information. Parameter values are set as in the base case environment. In addition, the dispersion of the market beliefs about the synergy is $\varepsilon=0.01$ in Panel A and $\varepsilon=0.1$ in Panel B. 
chooses, its rival responds by issuing a different amount of debt. Therefore we arrive at an asymmetric equilibrium as in the perfect information case. In this equilibrium one bidder selects a relatively high coupon payments, enjoys greater tax benefits, and is likely to lose the takeover contest. The other bidder chooses a low coupon and is likely to win the takeover contest. Also, consistent with the intuition discussed above it is not optimal to marginally undercut one's rival in leverage. For example, when the coupon payment of bidder 2 is $c_{2, b}=0.4$, the best response of bidder 1 is not to set its coupon to $0.4-\varepsilon$ (which is the optimal strategy in the perfect information case), but to set it instead to 0.35 to increase the probability of winning the contest.

When uncertainty is substantial, the asymmetric equilibrium falls apart. If a bidder has imprecise knowledge about the surplus parameter of the other bidder, then it becomes optimal to raise its coupon to a high level and increase tax benefits. If uncertainty is high, each bidder can predict the outcome of the takeover contest with only a low degree of accuracy. Therefore, the strategic role of debt becomes muted and the usual trade-off between tax benefits and bankruptcy costs produces a dominant effect on leverage choices. This logic is illustrated in Fig. 6, Panel B, which provides bidders' best response curves for the same set of parameters as Fig. 6, Panel A, with $\varepsilon=0.1$.

It follows from Panel $\mathrm{B}$ that the best response curves of the two bidders intersect at the point $\left(c_{1, b}, c_{2, b}\right)=(0.52,0.52)$. Thus, the equilibrium is now symmetric and the pair of equilibrium financing strategies is $\left(c_{1, b}^{*}, c_{2, b}^{*}\right)=(0.52,0.52)$. If a bidder has imprecise knowledge about the synergy parameter of the other bidder, then it becomes unlikely that changing capital structure helps this bidder win the takeover contest. If the synergy profit parameter of the other bidder is considerably higher than its own synergy profit parameter, then the first bidder loses the takeover contest regardless of its capital structure. Thus the best strategy is to select the coupon payment that best balances tax benefits and bankruptcy costs. Likewise, if the synergy parameter of bidder 2 is considerably lower than that of bidder 1 , then bidder 1 is likely to win, no matter how much debt it issues.

If the synergy parameter of bidder $i$ is more uncertain than that of bidder $j$ and if the spread is sufficiently large, then the value of bidder $i$ can exceed the value of bidder $j$ (even when $\Pi_{i, b}=\Pi_{j, b}$ ). Suppose, for example, that the synergy parameter of bidder 1 is $\Lambda=0.2$ and is known with certainty to both players. By contrast, bidder 1 does not know the synergy parameter of bidder 2 and believes that it is uniformly distributed on the interval [0.1,0.3] (as in Fig. 6, Panel B). Then the optimal coupon of bidder 2 is $0.52-\lambda$, where $\lambda$ is arbitrarily small. By setting its coupon at this value, bidder 2 wins the takeover contest. However, the high degree of uncertainty prevents the shareholders of bidder 1 from realizing that they will lose the takeover contest and forces them to set their coupon at 0.52 . Therefore a bidder has an incentive not to disclose its synergy parameter to a competing bidder, while trying to obtain specific information about the synergy value of its rival.

\section{Empirical implications and conclusions}

We begin this final section by reviewing the paper's empirical implications in light of the empirical evidence on the relation between financing decisions and control transactions.

\subsection{Empirical implications}

Our model allows us to make a number of predictions on the relation between capital structure and the timing and terms of control transactions. In particular our model predicts that the bidder with the lower leverage is likely to win in a takeover contest and that the premium paid to the target should decrease with the leverage of the winning bidder (as long as $\eta$, the share of the surplus captured by target shareholders, is positive). The model also predicts that the winner of the takeover contest should lever up after the takeover consummation.

Using a sample of mergers from 1963 to 1979, Bruner (1988) shows that, before the merger, bidders are significantly less levered than a control sample of firms. Bruner also reports that, within the first year of merger consummation, the bidders' leverage rises significantly when compared with a control sample. Ghosh and Jain (2000) reach a similar conclusion using a sample of 239 mergers completed between 1978 and 1987. Welch 
(2004) reports that "firms that have engaged in takeover activity tend to increase leverage." He also finds that this is the second best proxy (after stock returns) for explaining debt ratio changes for Compustat firms. Clayton and Ravid (2002) find empirical support for the prediction that firms with higher leverage are likely to lose bidding contests.

In a more recent study, Uysal (2006) provides direct evidence supporting our results. His source for identifying control transactions is the Securities Data Company's (SDC) US Mergers \& Acquisitions database. Using a sample of 998 takeover attempts between 1986 and 2001, and a two-step estimation procedure, Uysal examines whether a bidder's leverage deficit (defined as the difference between a firm's target leverage and its current leverage ratio) affects the premium paid by the bidder and the likelihood of the offer success. Specifically, he first estimates the target leverage ratio. For every year, firms in the bottom quartile leverage deficits are then defined as underleveraged. In a second stage, he finds that underleveraged firms pay higher premiums than other bidders and are more likely to successfully acquire targets. ${ }^{8}$ In addition, leverage deficit, defined as actual leverage minus the target leverage, subsumes other factors such as cash slack and current debt that had been found to be important predictors of the premium paid to the target. Uysal also finds that the book leverage ratio of underleveraged bidders increases by $10 \%$ following the acquisition. In Appendix B we report some additional empirical tests that provide further support for these predictions of the model.

While some evidence exists that firms' financing decisions depend on firm or industry characteristics, relatively little work relates these factors to the dispersion of industry leverage ratios. Our model predicts that intra-industry variation in financial structure relates to industry factors and that real and financial decisions should be jointly determined.

In particular, our model helps explain why otherwise identical firms could choose to have different leverage ratios. In our asymmetric equilibrium one firm decides to have a lower leverage ratio to receive some of the NPV of the investment opportunity. The other firm makes up for the loss of the growth opportunity by selecting a higher debt level, which is associated with greater tax benefits. Thus, in the model two ex ante identical firms optimally choose asymmetric strategies. One becomes a growth firm, selects a low leverage ratio, and invests. The other becomes a value firm, selects a higher leverage ratio, and does not invest. In this equilibrium the growth firm ends up with a lower leverage ratio.

This prediction of the model is consistent with the negative relation between market leverage (measured as the value of debt divided by the market value of the firm) and growth options shown in the literature examining the relation between firms' leverage choices and the composition of their investment opportunity sets. For example, Bradley, Jarrell, and Kim (1984) show that industries associated with high growth opportunities tend to have low market leverage. Smith and Watts (1992) and Barclay, Morellec, and Smith (2006) show using Compustat data a negative relation between market leverage and the market-to-book ratio, a commonly used proxy for growth options. Rajan and Zingales (1995) extend this analysis to show that the relation between market leverage and the market-to-book ratio is negative and significant across seven different countries.

Our results are also consistent with the evidence on leverage, product market competition, and investment. For example, Chevalier (1995) reports that unleveraged supermarket chains are more likely to open stores where competitors have recently experienced a leverage buyout. Using plant level data, Kovenock and Phillips (1997) find that highly leveraged firms in concentrated industries are less likely to increase investment.

Our model also relates the intra-industry variation in financial structure to industry factors. Notably, we predict that the dispersion in industry leverage ratios should be positively related to the state of the industry. To test this prediction of the model, we examine in Fig. 7 the drift of the leverage deficit within a five year window around the takeover announcement. Our source for identifying control transactions is the SDC US Mergers \& Acquisitions database. We apply a number of filters described in Appendix B to a preliminary sample that begins on January 1, 1980 and ends on December 31, 2005. Our final sample consists of 1926 takeover transactions.

\footnotetext{
${ }^{8}$ In Uysal's sample, underleveraged firms are $6 \%$ more likely to successfully acquire their target $(P$-value of 0.049$)$. This result is consistent with the implications of our model.
} 


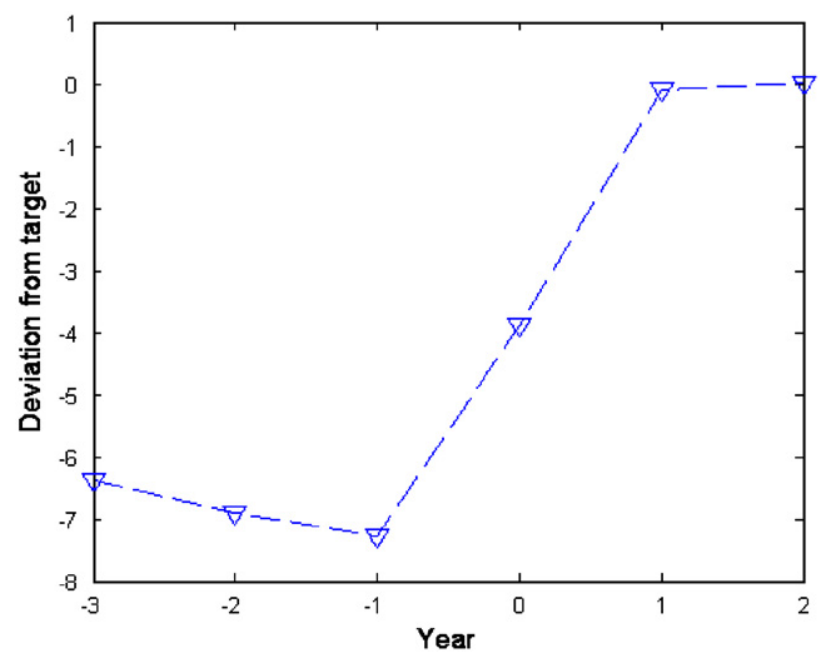

Fig. 7. Deviation from target leverage. Panel A plots the dynamics of leverage deficit of winning bidders around takeover announcements. The sample period is $1980-2005$.

The leverage deficit is defined as the deviation from target leverage. Fitted values from the regression of market leverage on the set of control variables described in Appendix B are used as a proxy for the target leverage. The results are plotted in Fig. 7.

As shown in Fig. 7, the leverage deficit of the winning bidders first increases slightly in absolute terms from year -3 to year -1 and then disappears in the year following takeover announcement. This pattern is consistent with the model's predictions. The shorter the time to the contemplated takeover transaction, the larger its impact on valuation and therefore the larger the degree of leverage asymmetry between the winning and the losing bidders. Because the losing bidder's leverage is set based on the traditional trade-off between tax benefits and bankruptcy costs, it should be well approximated by the fitted value from the target leverage regression. The deviation of the winning bidder's leverage from the target can then be interpreted as a measure of asymmetry in capital structures of competing bidders.

\subsection{Conclusions}

This paper analyzes the interaction between financial leverage and takeover activity. It develops a dynamic model of takeovers in which the financing strategies of the bidding firms and the timing and terms of takeovers are jointly determined. In the paper, capital structure plays the role of a commitment device and determines the outcome of the acquisition contest. We show that the possibility to grow externally through control transactions generates an asymmetric equilibrium in financing strategies, in which the bidder with the lowest leverage wins the takeover contest. In equilibrium, the leverage ratio of the winning bidder is significantly lower than the leverage ratio that best balances bankruptcy costs with the tax benefits of debt.

The model generates implications that are consistent with the available empirical evidence and yields a number of new predictions. In particular, the model predicts that a bidder with the lower leverage is likely to win in a takeover contest (unless the target firm is highly levered). Following the logic of the model, one would also expect the winner of the contest to lever up after the takeover consummation. The model also relates the dispersion in industry leverage ratios to various industry characteristics, such as the cash flow volatility, bankruptcy costs, and the state of the industry.

\section{Appendix A. Proofs}

Proof of Proposition 1. Denote the value of the bidder's equity after the takeover by $E_{i, j}\left(X, c_{i, j}\right)$. In the region for the industry shock where there is no default, the instantaneous change in the value of the equity satisfies 
the ordinary differential equation

$$
r E_{i, j}\left(X, c_{i, j}\right)=(1-\tau)\left[\Pi_{j} X-c_{i, j}\right]+\mu X \frac{\partial E_{i, j}\left(X, c_{i, j}\right)}{\partial X}+\frac{1}{2} \sigma^{2} X^{2} \frac{\partial^{2} E_{i, j}\left(X, c_{i, j}\right)}{\partial X^{2}} .
$$

The solution of Eq. (22) is given by

$$
E_{i, j}\left(X, c_{i, j}\right)=A X^{\xi}+B X^{v}+(1-\tau)\left[\frac{\Pi_{j} X}{r-\mu}-\frac{c_{i, j}}{r}\right],
$$

where $\xi$ and $v$ are the positive and negative roots of the equation $\frac{1}{2} \sigma^{2} y(y-1)+\mu y-r=0$. In this paper, we consider a stock based definition of default whereby shareholders inject funds in the firm as long as equity value is positive. This condition implies that shareholders default on their debt obligations the first time equity value is equal to zero. As a result, the constants $A$ and $B$ together with the equity value-maximizing default threshold $\underline{X}_{j}$ are determined through the set of boundary conditions:

$$
\begin{aligned}
& E_{i, j}\left(\underline{X}_{j}, c_{i, j}\right)=0, \\
& \left.\frac{\partial E_{i, j}\left(X, c_{i, j}\right)}{\partial X}\right|_{X=\underline{X}_{j}}=0, \quad \text { and } \\
& \lim _{X \rightarrow \infty} \frac{E_{i, j}\left(X, c_{i, j}\right)}{X}<+\infty .
\end{aligned}
$$

Simple algebraic derivations yield the desired result.

Proof of Proposition 2. Our aim is to show that the maximum price that a bidding firm is willing to pay to acquire the target, $\Delta E\left(X, c_{i, b}\right)$, decreases with $c_{i, b}$ and increases with $X$. Replacing $\underline{X}_{j}$ by its expression in Eq. (5) and using the fact that $c_{i, o}=c_{i, b}$ yields

$$
\Delta E\left(X, c_{i, b}\right)=(1-\tau)\left\{\frac{\Pi_{m}-\Pi_{o}}{r-\mu} X-\frac{c_{\mathrm{tar}}}{r}-A\left[c_{i, m}\left(\frac{\Pi_{m}}{c_{i, m}}\right)^{v}+c_{i, b}\left(\frac{\Pi_{o}}{c_{i, b}}\right)^{v}\right]\right\},
$$

where $c_{i, m}=c_{i, b}+c_{\text {tar }}$ and

$$
A=\frac{1}{r(v-1)}\left[\frac{r(v-1) X}{v(r-\mu)}\right]^{v}<0 .
$$

The partial derivatives of $\Delta E\left(X, c_{i, b}\right)$ with respect to $c_{i, b}$ and $X$ are:

$$
\begin{aligned}
\frac{\partial \Delta E\left(X, c_{i, b}\right)}{\partial c_{i, b}}= & -(1-\tau)(1-v) A\left[\left(\frac{\Pi_{m}}{c_{i, m}}\right)^{v}-\left(\frac{\Pi_{o}}{c_{i, b}}\right)^{v}\right], \\
\frac{\partial \Delta E\left(X, c_{i, b}\right)}{\partial X}= & (1-\tau) \frac{\Pi_{m}-\Pi_{o}}{r-\mu} \\
& +\frac{1-\tau}{r-\mu}\left[\frac{r(v-1) X}{v(r-\mu)}\right]^{v-1}\left[\left(\frac{c_{i, b}}{\Pi_{o}}\right)^{1-v}-\left(\frac{c_{i, m}}{\Pi_{m}}\right)^{1-v}\right] .
\end{aligned}
$$

Under the condition $c_{\text {tar }} \Pi_{o}<c_{i, b}\left(\Pi_{m}-\Pi_{o}\right)$, we have $\partial \Delta E\left(X, c_{i, b}\right) / \partial c_{i, b}<0$. In addition, the above analysis makes sense only for $X>\underline{X}_{o}$. Also, it follows from (30) that $\partial^{2} \Delta E\left(X, c_{i, b}\right) / \partial^{2} X<0$. Therefore, it is sufficient to prove that

$$
\left.\frac{\partial \Delta E\left(X, c_{i, b}\right)}{\partial X}\right|_{X=\underline{X}_{o}}>0 .
$$


Plugging Eq. (4) into (30) yields

$$
\left.\frac{\partial \Delta E\left(X, c_{i, b}\right)}{\partial X}\right|_{X=\underline{X}_{o}}=(1-\tau) \frac{\Pi_{m}-\Pi_{o}}{r-\mu}+\frac{1-\tau}{r-\mu}\left[1-\left(\frac{c_{i, m} \Pi_{o}}{c_{i, b} \Pi_{m}}\right)^{1-v}\right] .
$$

The term in the square bracket is positive, which establishes the desired result.

Proof of Proposition 4. Assume that $X_{0} \in\left(\underline{X}_{1}, \bar{X}\right)$. In this region for the industry shock where there is no default and no takeover, the instantaneous change in the value of the target's equity satisfies

$$
r E_{\mathrm{tar}}\left(X, c_{\mathrm{tar}}\right)=(1-\tau)\left(\Pi_{\mathrm{tar}} X-c_{\mathrm{tar}}\right)+\mathbb{E}\left[d E_{\mathrm{tar}}\left(X, c_{\mathrm{tar}}\right)\right],
$$

the solution to which is given by

$$
E_{\mathrm{tar}}\left(X, c_{\mathrm{tar}}\right)=A X^{\xi}+B X^{v}+(1-\tau)\left(\frac{\Pi_{\mathrm{tar}} X}{r-\mu}-\frac{c_{\mathrm{tar}}}{r}\right)
$$

To determine the values of $A, B$, and $\bar{X}$, we use the boundary conditions for equity value at $\underline{X}_{1}$ and $\bar{X}$. Once bidder 1 has defaulted, takeovers are precluded. As a result, the value of equity when $X=\underline{X}_{1}$ is

$$
\left.E_{\mathrm{tar}}\left(X, c_{\mathrm{tar}}\right)\right|_{X=\underline{X}_{1}}=(1-\tau)\left\{\frac{\Pi_{\mathrm{tar}} \underline{X}_{1}}{r-\mu}-\frac{c_{\mathrm{tar}}}{r}+\frac{c_{\mathrm{tar}}}{r(1-v)}\left(\frac{\underline{X}_{1}}{\underline{X}_{\mathrm{tar}}}\right)^{v}\right\},
$$

where $\underline{X}_{\operatorname{tar}}$ is the default threshold selected by target shareholders defined by

$$
\underline{X}_{\mathrm{tar}}=\frac{v}{v-1} \frac{c_{\mathrm{tar}}(r-\mu)}{\Pi_{\mathrm{tar}} r} .
$$

The first term on the right hand side of this value-matching condition is the present value of a perpetual entitlement to the current flow of income. The second term represents the value of target shareholders' option to default. Because target shareholders do not choose the default threshold $X_{1}$, this value-matching condition is not associated with a smooth-pasting condition. Consider next the choice of the takeover threshold $\bar{X}$. When $X=\bar{X}$, the value of equity satisfies the value-matching condition

$$
\left.E_{\mathrm{tar}}\left(X, c_{\mathrm{tar}}\right)\right|_{X=\bar{X}}=\Delta E\left(\bar{X}, c_{i, b}\right)+\eta\left[\Delta E\left(\bar{X}, c_{j, b}\right)-\Delta E\left(\bar{X}, c_{i, b}\right)\right]-K .
$$

Using Eqs. (35) and (37) and simple calculations, we get

$$
\begin{aligned}
A= & \frac{\left\{\Delta E\left(\bar{X}, c_{i, b}\right)+\eta\left[\Delta E\left(\bar{X}, c_{j, b}\right)-\Delta E\left(\bar{X}, c_{i, b}\right)\right]-K\right\} \underline{X}_{1}^{v}}{\bar{X}^{\xi} \underline{X}_{1}^{v}-\underline{X}_{1}^{\xi} \bar{X}^{v}} \\
& -\frac{(1-\tau)\left[\frac{\Pi_{\mathrm{tar}} \bar{X}}{r-\mu}-\frac{c_{\mathrm{tar}}}{r}\right] \underline{X}_{1}^{v}+(1-\tau) \frac{c_{\mathrm{tar}}}{r(1-v)} \bar{X}^{v}\left(\frac{\underline{X}_{1}}{\underline{X}_{\mathrm{tar}}}\right)^{v}}{\bar{X}^{\xi} \underline{X}_{1}^{v}-\underline{X}_{1}^{\xi} \bar{X}^{v}}
\end{aligned}
$$

and

$$
\begin{aligned}
B= & \frac{\left\{\Delta E\left(\bar{X}, c_{i, b}\right)+\eta\left[\Delta E\left(\bar{X}, c_{j, b}\right)-\Delta E\left(\bar{X}, c_{i, b}\right)\right]-K\right\} \underline{X}_{1}^{\xi}}{\bar{X}^{v} \underline{X}_{1}^{\xi}-\underline{X}_{1}^{v} \bar{X}^{\xi}} \\
& -\frac{(1-\tau)\left[\frac{\Pi_{\mathrm{tar}} \bar{X}}{r-\mu}-\frac{c_{\mathrm{tar}}}{r}\right] \underline{X}_{1}^{\xi}+(1-\tau) \frac{c_{\mathrm{tar}}}{r(1-v)} \bar{X}^{\xi}\left(\frac{\underline{X}_{1}}{\underline{X}_{\mathrm{tar}}}\right)^{v}}{\bar{X}^{v} \underline{X}_{1}^{\xi}-\underline{X}_{1}^{v} \bar{X}^{\xi}} .
\end{aligned}
$$


Simplifying these expressions yields

$$
\begin{aligned}
E_{\mathrm{tar}}\left(X, c_{\mathrm{tar}}\right)= & (1-\tau)\left(\frac{\Pi_{\mathrm{tar}} X}{r-\mu}-\frac{c_{\mathrm{tar}}}{r}\right)+\mathscr{L}\left(X ; \underline{X}_{1}, y\right)\left(\frac{\underline{X}_{1}}{\underline{X}_{\mathrm{tar}}}\right)^{v} \frac{(1-\tau) c_{\mathrm{tar}}}{r(1-v)} \\
& -\mathscr{H}\left(X ; \underline{X}_{1}, y\right)\left[K+(1-\tau)\left(\frac{\Pi_{\mathrm{tar}} \bar{X}}{r-\mu}-\frac{c_{\mathrm{tar}}}{r}\right)\right] \\
& +\mathscr{H}\left(X ; \underline{X}_{1}, y\right)\left\{\Delta E\left(\bar{X}, c_{i, b}\right)+\eta\left[\Delta E\left(\bar{X}, c_{j, b}\right)-\Delta E\left(\bar{X}, c_{i, b}\right)\right]\right\} .
\end{aligned}
$$

This expression is valid for any takeover threshold $\bar{X}$. Because the first term on the right-hand side does not depend on $\bar{X}$, the threshold $\bar{X}$ is the solution to the following maximization problem:

$$
\bar{X}=\underset{y}{\arg \max }\left\{(1-\tau) \mathscr{L}\left(X ; \underline{X}_{1}, y\right)\left(\frac{\underline{X}_{1}}{\underline{X}_{\mathrm{tar}}}\right)^{v} \frac{c_{\mathrm{tar}}}{r(1-v)}+\mathscr{H}\left(X ; \underline{X}_{1}, y\right) F(y)\right\} .
$$

Proof of Proposition 5. The objective function of target shareholders, given by Eq. (7) can then be written as

$$
\begin{aligned}
\mathscr{M}\left(y, c_{i, b}\right)= & \frac{y^{\xi} X^{v}-y^{v} X^{\xi}}{y^{\xi} \underline{X}_{1}^{v}-y^{v} \underline{X}_{1}^{\xi}}\left(\frac{\underline{X}_{1}}{\underline{X}_{\mathrm{tar}}}\right)^{v} \frac{c_{\mathrm{tar}}}{r(1-v)} \\
& +\frac{X^{\xi} \underline{X}_{1}^{v}-X^{v} \underline{X}_{1}^{\xi}}{y^{\xi} \underline{X}_{1}^{v}-y^{v} \underline{X}_{1}^{\xi}}\left\{\frac{y\left(\Pi_{b}+\Lambda-\Pi_{o}\right)}{r-\mu}-\frac{K}{1-\tau}\right\}+\frac{X^{\xi} \underline{X}_{1}^{v}-X^{v} \underline{X}_{1}^{\xi}}{y^{\xi} \underline{X}_{1}^{v}-y^{v} \underline{X}_{1}^{\xi}} \frac{y^{v}}{r(v-1)} \\
& \times\left\{(1-\eta)\left[\frac{c_{i, b}+c_{\mathrm{tar}}}{\underline{X}_{m}^{v}\left(c_{i, b}\right)}-\frac{c_{i, b}}{\underline{X}_{o}^{v}\left(c_{i, b}\right)}\right]+\eta\left[\frac{c_{j, b}+c_{\mathrm{tar}}}{\underline{X}_{m}^{v}\left(c_{j, b}\right)}-\frac{c_{j, b}}{\underline{X}_{o}^{v}\left(c_{j, b}\right)}\right]\right\} .
\end{aligned}
$$

Taking the partial derivative of the objective function with respect to $y$ yields (after simplifications)

$$
\frac{\partial \mathscr{M}\left(y, c_{i, b}\right)}{\partial y}=\frac{X^{\xi} \underline{X}_{1}^{v}-\underline{X}_{1}^{\xi} X^{v}}{\left[y^{\xi} \underline{X}_{1}^{v}-y^{v} \underline{X}_{1}^{\xi}\right]^{2}}\left\{G(y)-D c_{\mathrm{tar}}\right\},
$$

where

$$
G(y)=A\left[y^{\xi} \underline{X}_{1}^{v}(1-\xi)+y^{v} \underline{X}_{1}^{\xi}(v-1)\right]+(B+C)(v-\xi) y^{v+\xi-1} \underline{X}_{1}^{v}-D \frac{K}{1-\tau}
$$

and $A, B, C$, and $D$ are constants defined by

$$
\begin{aligned}
A & =\frac{\Pi_{b}+\Lambda-\Pi_{o}}{r-\mu}>0, \\
B & =\frac{1-\eta}{r(1-v)}\left[\frac{r(v-1)}{v(r-\mu)}\right]^{v}\left(\left[c_{i, b}+c_{\mathrm{tar}}\right]^{1-v} \Pi_{m}^{v}-c_{i, b}^{1-v} \Pi_{o}^{v}\right), \\
C & =\frac{\eta}{r(1-v)}\left[\frac{r(v-1)}{v(r-\mu)}\right]^{v}\left(\left[c_{j, b}+c_{\mathrm{tar}}\right]^{1-v} \Pi_{m}^{v}-c_{j, b}^{1-v} \Pi_{o}^{v}\right), \\
D & =v y^{\beta_{2}-1} \underline{X}_{1}^{\xi}-\xi y^{\xi-1} \underline{X}_{1}^{v}-E, \\
E & =\frac{y^{v+\xi-1}(v-\xi)}{r(1-v)}\left(\frac{\underline{X}_{1}}{\underline{X}_{\mathrm{tar}}}\right)^{v} .
\end{aligned}
$$

Therefore, the first order condition $\partial \mathscr{M}\left(y, c_{i, b}\right) / \partial y=0$ is satisfied for

$$
K^{*}(y)=(1-\tau) \frac{A\left[y^{\xi} \underline{X}_{1}^{v}(1-\xi)+y^{v} \underline{X}_{1}^{\xi}(v-1)\right]+(B+C)(v-\xi) y^{v+\xi-1} \underline{X}_{1}^{v}-E c_{\mathrm{tar}}}{D} .
$$

$K^{*}(y)$ does not depend on the initial state of the stochastic shock, $X$. To prove that the correspondence $K^{*}(y)$ is one-to-one for sufficiently large $K$, it can be shown that

$$
\lim _{y \uparrow \infty} \frac{\partial K^{*}(y)}{\partial y}=(1-\tau) A \frac{\xi-1}{\xi}>0 .
$$


Therefore there exists some $X^{\text {sup }}$ such that $K^{*}\left(X^{\text {sup }}\right)>0$, and for any $y>X^{\text {sup }}, \partial K^{*}(y) / \partial y>\varepsilon$ for some $\varepsilon>0$. It follows that there exists $X^{*} \geqslant X^{\text {sup }}$ such that $K^{*}(y)>0$ is a one-to-one correspondence in the region $\left[X^{*},+\infty\right) \times\left[K^{*}\left(X^{*}\right),+\infty\right)$.

Proof of Proposition 6 and 7. Similar to the proof of Proposition 4.

Stock mergers: In this section we focus on the role of leverage in stock mergers, instead of cash offers. Specifically, we assume that bidders submit bids as fractions of the equity of the combined entity that they are willing to grant to target shareholders. The bidder with the highest bid value wins the takeover contest. We argue that even though the negotiation mechanism of stock mergers is different from that of cash offers, the main results of the previous section are valid for stock mergers as well.

Let $f_{i}$ be the fraction of the equity of the merged firm that is owned by bidder $i$ 's shareholders $i(i=1,2)$ if they win the takeover contest. Target shareholders then own a fraction of $1-f_{i}$. The value of the equity holdings in the combined entity owned by bidder $i$ is given by Proposition 1:

$$
E_{i, m}\left(X, c_{i, m}\right)=f_{i}(1-\tau)\left[\frac{\Pi_{m} X}{r-\mu}-\frac{c_{i, m}}{r}-\left(\frac{X}{\underline{X}_{m}}\right)^{v}\left(\frac{\Pi_{m} \underline{X}_{m}}{r-\mu}-\frac{c_{i, m}}{r}\right)\right],
$$

where $c_{i, m}=c_{i, b}+c_{\mathrm{tar}}$. Bidder $i$ is indifferent between winning the takeover contest and becoming an outsider if $f_{i}=f_{i}^{*}$, where

$$
f_{i}^{*} E_{i, m}\left(X, c_{i, m}\right)=E_{i, o}\left(X, c_{i, o}\right) .
$$

It is easy to check that if $f_{i}=f_{i}^{*}$, then the bidder's equity values coincide in these two scenarios. For any fraction of equity $f_{i}$ exceeding $f_{i}^{*}$, bidder $i$ is strictly better off by merging, while in the case $f_{i}<f_{i}^{*}$, bidder 1 strictly prefers losing the takeover contest.

Target shareholders then hold a claim to the remaining shares of the merged firm. The value of this claim is given by

$$
\begin{aligned}
& \left(1-f_{i}^{*}\right) E_{i, m}\left(X, c_{i, m}\right) \\
& \quad=(1-\tau)\left[\frac{x\left(\Pi_{m}-\Pi_{o}\right)}{r-\mu}-\frac{c_{\mathrm{tar}}}{r}-\frac{c_{i, b}+c_{\mathrm{tar}}}{r(v-1)}\left(\frac{X}{\underline{X}_{m}}\right)^{v}+\frac{c_{i, o}}{r(v-1)}\left(\frac{X}{\underline{X}_{o}}\right)^{v}\right] .
\end{aligned}
$$

This value is identical to the reservation value $\Delta E\left(X, c_{1, b}\right)$ given by Eq. (5). Thus, it does not matter whether target shareholders are compensated in cash or in stock. In both cases, the mechanism of extracting premium from the bidders is the same. The total value of the equilibrium premium accrued to target shareholders does not depend on the form of compensation. The properties of the equilibrium premium, specified by Proposition 2, apply to the case of stock mergers as well. In particular, Proposition 2 establishes the monotonicity of the acquisition price in $c_{i, b}$ for any given state of the stochastic shock $X$.

In stock offers, the value of the target's holdings in the merged entity decreases with $f_{i}$. On the contrary, the value of a bidder's holdings increases with $f_{i}$. As long as this value exceeds the equity value of an outsider for both bidders, they have an incentive to place a higher bid (offer a higher fraction of equity to target shareholders). This incentive disappears for the bidder with the higher coupon (bidder 1) when $f_{1}=f_{1}^{*}\left(c_{1, b}\right)$. The equilibrium strategy for bidder 2 is then to offer a fraction $1-\widehat{f}_{2}+\varepsilon$, where $\widehat{f}_{2}$ is determined by matching the reservation value of bidder 1 with the value of bidder 2's bid:

$$
\left(1-f_{1}^{*}\right) E_{1, m}\left(X, c_{1, m}\right)=\left(1-\widehat{f}_{2}\right) E_{2, m}\left(X, c_{2, m}\right) .
$$

In equilibrium, bidder 1 bids $1-f_{1}^{*}\left(c_{1, b}\right)$ and loses the takeover contest.

The above arguments imply that even though the negotiation mechanisms are different in the cases of cash offers and stock mergers, the equilibrium value of the premium captured by the target is the same and is given by Eq. (5). Because it is the value of the premium that determines the timing of the merger and the properties of the equilibrium, all results obtained in the main text apply to the case of stock mergers as well. 


\section{Appendix B. Empirical tests}

In this Appendix we perform exploratory tests of the model's predictions. Our source for identifying control transactions is the SDC US Mergers \& Acquisitions database. We apply the following six filters to a preliminary sample that begins on January 1, 1980 and ends on December 31, 2005 (1) The acquirer and the target are public firms. (2) The acquirer's financial information is available in the Compustat annual tapes. (3) We exclude transactions where the acquirer held more than $10 \%$ of the target's stock prior to takeover announcement. (4) The deal value is available form SDC and is at least $\$ 10$ million. (5) The percent of shares acquired in the deal is $50 \%$ or higher. (6) Financial firms [Standard Industrial Classification (SIC) codes 6000 and higher] are excluded.

Our final sample consists of 1926 takeover transactions. Table A1 provides the descriptive statistics for our sample of successful bidders as well as for the universe of all Compustat firms in the same sample period. We specifically focus on market leverage, because most of our model predictions center around market leverage of winning bidders in takeover contests. Market leverage is defined as the ratio of the sum of long-term debt and debt in current liabilities to the sum of long-term debt, debt in current liabilities and the total value of common stock. (Our results are robust to alternative definitions of market leverage.) The data for winning bidders are obtained one year prior to takeover announcements.

The results reported in Table A1 show that winning bidders are on average larger firms with higher marketto-book ratios. The market-to-book ratio is a typical empirical proxy for the value of a firm's growth opportunities. Therefore it is the growth firms that, on average, successfully acquire other companies. This evidence is consistent with our model that predicts that ex ante identical firms follow asymmetric strategies: One uses more debt and does not invest, while the other becomes a growth firm, uses less debt, and invests (e.g. successfully accomplishes a takeover transaction). The evidence presented in Table A1 also supports the major prediction of our model that the winning bidders are expected to be less levered before takeover transactions than the losing ones (and other firms that do not participate in takeover contests).

While useful for illustrating purposes, the direct comparison of leverage ratios of firms within our sample cannot be used for drawing any sound statistical inference, because of the differences in firm characteristics over time and across industries. Different firms are likely to have different target leverage ratios. Therefore, to measure the impact of takeovers on market leverage, we have to account for the set of potential determinants of capital structure used in prior studies. This set includes proxies for size, growth opportunities, tangibility of assets, costs of financial distress, and profitability. These determinants of capital structure are described below:

Size: Larger firms are considered to be more diversified and, therefore, less prone to bankruptcy. Thus, leverage should be positively related to size. A common definition of size in the empirical capital structure literature is the logarithm of a firm's annual sales. To measure sales in constant dollars, we divide the nominal sales by the consumer price index at the end of the respective year.

Regulation: Conflicts of interests between stockholders and debtholders are less severe in regulated industries than in unregulated ones. Therefore, firms in regulated industries are expected to have higher leverage ratios. We define railroads (SIC code 4011) before 1981, trucking (SIC codes 4210 and 4213) before

Table A1

\begin{tabular}{lccc}
\hline Firm characteristics & Mean & Median & Standard deviation \\
\hline Market leverage & & & 0.185 \\
All firms & 0.258 & 0.141 & 0.254 \\
Winning bidders & 0.196 & & 0.191 \\
Market-to-book & & 1.10 & 2.21 \\
All firms & 1.76 & 1.39 & 2.57 \\
Winning bidders & 2.12 & & 2.35 \\
Size (log Sales) & & 9.07 & 1.92 \\
All firms & 9.08 & 11.16 & \\
Winning bidders & 11.11 & &
\end{tabular}


1981, airlines (SIC code 4512) before 1979, telecommunications (SIC codes 4812 and 4813) before 1983, and gas and electric utilities (SIC codes 4900 to 4939) as regulated.

Costs of financial distress: Consistent with the trade-off theory, Titman and Wessels (1988) find a negative relation between expected costs of financial distress and leverage. Following Titman and Wessels, we define a costly liquidation dummy that takes the value of one if a firm produces machines and equipment (SIC codes 3400-3999).

Tangibility: Tangible assets are easy to collateralize, and, therefore, they reduce the agency costs of debt. We follow Rajan and Zingales (1995) in measuring tangibility as the ratio of fixed to total assets.

Profitability: Based on different theories of optimal capital structure, a firm's profitability should be negatively related to its leverage. We measure profitability as the ratio of a firm's operating income to its sales.

The evidence presented in Table Al suggests that winning bidders are, on average, underlevered prior to takeover transactions. To gauge the magnitude of this effect, we regress the market leverage of firms in our sample on the set of control variables and a set of time dummies, equaling one if the firm becomes a successful bidder in one, two, or three years or has recently completed a takeover deal. In order to control for industry fixed effects, we convert both dependent and independent variables into deviations from two-digit SIC industry means. To get rid of extreme outliers and exclude zero-leverage firms, we windsorize observations in the top and bottom $1 \%$ groups for both dependent and independent variables. Table A2 presents our results. $T$-statistics are reported in brackets. The dummies BEFORE3, BEFORE2, and BEFORE1 are set to one if the firm becomes a successful bidder in three, two, and one years, respectively. The dummies AFTER 1 and $A F T E R 2$ are set equal to 1 for firms that were successful acquirers in takeover deals announced in the previous year (respectively two years ago).

Consistent with prior empirical studies, market leverage is negatively related to market-to-book ratio, profitability, and costs of financial distress and positively related to tangibility, size, and regulation. In addition, strong evidence suggests that winning bidders are underleveraged prior to takeover announcements and that they increase leverage in the following year. The regression coefficients on BEFORE3, BEFORE2, and $B E F O R E 1$ are all negative and statistically significant suggesting that on average successful bidders are

Table A2

Regressions of market leverage on successful bidder dummies

\begin{tabular}{|c|c|c|c|c|c|}
\hline Intercept & $\begin{array}{c}0.015 \\
{[17.91]}\end{array}$ & $\begin{array}{c}0.015 \\
{[18.05]}\end{array}$ & $\begin{array}{c}0.015 \\
{[18.20]}\end{array}$ & $\begin{array}{c}0.015 \\
{[17.20]}\end{array}$ & $\begin{array}{c}0.015 \\
{[17.13]}\end{array}$ \\
\hline Market-to-book & $\begin{array}{c}5.7 \times 10^{-5} \\
{[1.95]}\end{array}$ & $\begin{array}{c}5.8 \times 10^{-5} \\
{[1.99]}\end{array}$ & $\begin{array}{c}5.7 \times 10^{-5} \\
{[1.95]}\end{array}$ & $\begin{array}{c}5.7 \times 10^{-5} \\
{[1.94]}\end{array}$ & $\begin{array}{c}5.7 \times 10^{-5} \\
{[1.95]}\end{array}$ \\
\hline Size & $\begin{array}{l}0.0078 \\
{[26.62]}\end{array}$ & $\begin{array}{l}0.0078 \\
{[26.84]}\end{array}$ & $\begin{array}{l}0.0078 \\
{[27.13]}\end{array}$ & $\begin{array}{l}0.0075 \\
{[25.55]}\end{array}$ & $\begin{array}{l}0.0075 \\
{[25.40]}\end{array}$ \\
\hline Profitability & $\begin{array}{c}-0.012 \\
{[-15.41]}\end{array}$ & $\begin{array}{c}-0.012 \\
{[-15.42]}\end{array}$ & $\begin{array}{c}-0.012 \\
{[-15.42]}\end{array}$ & $\begin{array}{c}-0.012 \\
{[-15.42]}\end{array}$ & $\begin{array}{c}-0.012 \\
{[-15.41]}\end{array}$ \\
\hline Tangibility & $\begin{array}{c}0.085 \\
{[57.60]}\end{array}$ & $\begin{array}{c}0.085 \\
{[57.55]}\end{array}$ & $\begin{array}{c}0.085 \\
{[57.33]}\end{array}$ & $\begin{array}{c}0.085 \\
{[57.75]}\end{array}$ & $\begin{array}{c}0.085 \\
{[57.76]}\end{array}$ \\
\hline Liquidation & $\begin{array}{l}-0.0177 \\
{[-12.90]}\end{array}$ & $\begin{array}{l}-0.0177 \\
{[-12.91]}\end{array}$ & $\begin{array}{l}-0.0178 \\
{[-12.94]}\end{array}$ & $\begin{array}{l}-0.0178 \\
{[-12.97]}\end{array}$ & $\begin{array}{l}-0.0178 \\
{[-12.97]}\end{array}$ \\
\hline Regulation & $\begin{array}{l}0.027 \\
{[5.76]}\end{array}$ & $\begin{array}{l}0.027 \\
{[5.74]}\end{array}$ & $\begin{array}{l}0.027 \\
{[5.74]}\end{array}$ & $\begin{array}{l}0.027 \\
{[5.78]}\end{array}$ & $\begin{array}{l}0.027 \\
{[5.78]}\end{array}$ \\
\hline BEFORE 3 & $\begin{array}{c}-0.059 \\
{[-10.62]}\end{array}$ & & & & \\
\hline BEFORE 2 & & $\begin{array}{c}-0.064 \\
{[-12.06]}\end{array}$ & & & \\
\hline BEFORE 1 & & & $\begin{array}{c}-0.068 \\
{[-13.42]}\end{array}$ & & \\
\hline AFTER 1 & & & & $\begin{array}{c}-0.00049 \\
{[-0.09]}\end{array}$ & \\
\hline AFTER 2 & & & & & $\begin{array}{c}0.0070 \\
{[1.22]}\end{array}$ \\
\hline$N$ & 131,134 & 131,134 & 131,134 & 131,134 & 131,134 \\
\hline
\end{tabular}


underlevered by about 6-7\%. This evidence is consistent with our predictions. The regression coefficients on $A F T E R 1$ and AFTER 2 are statistically insignificant, suggesting that the successful bidders increase their leverage following takeovers and eliminate leverage deficit. ${ }^{9}$

\section{References}

Alderson, M., Betker, B., 1995. Liquidation costs and capital structure. Journal of Financial Economics 39, 45-69.

Andrade, G., Stafford, E., 2004. Investigating the economic role of mergers. Journal of Corporate Finance 10, 1-36.

Andrade, G., Mitchell, M., Stafford, E., 2001. New evidence and perspectives on mergers. Journal of Economic Perspectives 15, 103-120.

Barclay, M., Morellec, E., Smith, C.W., 2006. On the debt capacity of growth options. Journal of Business 79, 37-59.

Bradley, M., Jarrell, G., Kim, E.H., 1984. On the existence of an optimal capital structure: theory and evidence. Journal of Finance 39, 857-878.

Bradley, M., Desai, A., Kim, E.H., 1988. Synergistic gains from corporate acquisitions and their division between the stockholders of target and acquiring firms. Journal of Financial Economics 21, 3-40.

Bruner, R., 1988. The use of excess cash and debt capacity as a motive for merger. Journal of Financial and Quantitative Analysis 23, 199-217.

Chava, S., Kumar, P., Warga, A., 2005. Agency costs and the pricing of bond covenants. Unpublished working paper. University of Houston, Houston, TX.

Chevalier, J., 1995. Debt and product market competition: local market entry, exit, and expansion decisions of supermarket chains. American Economic Review 85, 415-435.

Clayton, M., Ravid, A., 2002. The effect of leverage on bidding behavior: theory and evidence from FCC auctions. Review of Financial Studies 15, 723-750.

De, S., Fedenia, M., Triantis, A., 1996. Effects of competition on bidder returns. Journal of Corporate Finance 2, $227-259$.

Fischer, E., Heinkel, R., Zechner, J., 1989. Dynamic capital structure choice: theory and tests. Journal of Finance 44, 19-40.

Ghosh, A., Jain, P., 2000. Financial leverage changes associated with corporate mergers. Journal of Corporate Finance 6, $377-402$.

Gilson, S., 1997. Transaction costs and capital structure choice: evidence from financially distressed firms. Journal of Finance 52, 161-196.

Goldstein, R., Ju, N., Leland, H., 2001. An ebit-based model of dynamic capital structure. Journal of Business 74, $483-512$.

Hackbarth, D., Morellec, E., 2008. Stock returns in mergers and acquisitions. Journal of Finance 63.

Hackbarth, D., Miao, J., Morellec, E., 2006. Capital structure, credit risk, and macroeconomic conditions. Journal of Financial Economics 82, 519-550.

Healey, P., Palepu, K., Ruback, R., 1992. Does corporate performance improve after mergers? Journal of Financial Economics 31, 135-175.

Ibbotson Associates, 2002. Stocks, Bonds, Bills, and Inflation: 2002 Yearbook, Ibbotson Associates, Chicago, IL.

Kovenock, D., Phillips, G., 1997. Capital structure and product market behavior: an examination of plant exit and investment decisions. Review of Financial Studies 10, 767-803.

Lambrecht, B., 2001. The impact of debt financing on entry and exit in a duopoly. Review of Financial Studies 14, $765-804$.

Lambrecht, B., 2004. The timing and terms of mergers motivated by economies of scale. Journal of Financial Economics 72 , 41-62.

Lambrecht, B., Myers, S., 2007. A theory of takeovers and disinvestment. Journal of Finance 62, 809-845.

Leland, H., 1994. Corporate debt value, bond covenants, and optimal capital structure. Journal of Finance 49, $1213-1252$.

Leland, H., 2007. On purely financial synergies and the optimal scope of the firm: implications for mergers, spinoffs, and structured finance. Journal of Finance 62, 765-807.

Margsiri, W., Mello, A., Ruckes, M., 2005. A dynamic analysis of growth via acquisitions. Unpublished working paper. University of Wisconsin, Madison, WI.

Mello, A., Parsons, J., 1992. Measuring the agency cost of debt. Journal of Finance 47, 1887-1904.

Mitchell, M., Mulherin, H., 1996. The impact of industry shocks on takeover and restructuring activity. Journal of Financial Economics 41, 193-229.

Miao, J., 2005. Optimal capital structure and industry dynamics. Journal of Finance 60, 2621-2659.

Morellec, E., 2001. Asset liquidity, capital structure and secured debt. Journal of Financial Economics 61, $173-206$.

Morellec, E., 2004. Can managerial discretion explain observed leverage ratios? Review of Financial Studies 17, $257-294$.

Morellec, E., Zhdanov, A., 2005. The dynamics of mergers and acquisitions. Journal of Financial Economics 77, 649-672.

Myers, S., 1977. The determinants of corporate borrowing. Journal of Financial Economics 5, 147-175.

Rajan, R., Zingales, L., 1995. What do we know about capital structure? Some evidence from international data. Journal of Finance 50, $1421-1460$.

Smith, C., Watts, R., 1992. The investment opportunity set and corporate financing, dividend, and compensation policies. Journal of Financial Economics 32, 262-292.

Strebulaev, I., 2007. Do tests of capital structure mean what they say? Journal of Finance 62, 1747-1787.

\footnotetext{
${ }^{9}$ Even though the model focuses on competition among bidders, explicit competition is not necessary to obtain the main results. As long as the winning bidder is aware of the presence of potential competitors that would outbid if should it place a low bid, all model predictions obtain. Therefore, it is not necessary to include a proxy for the presense of competing bids in the leverage regressions.
} 
Titman, S., Wessels, R., 1988. The determinants of capital structure choice. Journal of Finance 43, 1-18.

Welch, I., 2004. Capital structure and stock returns. Journal of Political Economy 112, 106-131.

Uysal, V., 2006. Deviation from the target capital structure and acquisition choices. Unpublished working paper. University of Oklahoma, Norman, OK.

Zhdanov, A., 2007. Competitive equilibrium with debt. Journal of Financial and Quantitative Analysis 42, 709-734.

Zwiebel, J., 1996. Dynamic capital structure under managerial entrenchment. American Economic Review 86, $1197-1215$. 